\title{
LA SOCIEDAD ANÓNIMA DE GARANTÍA RECÍPROCA EN CHILE; PRECISIONES Y PROPUESTAS PARA UN NUEVO SISTEMA DE GARANTÍAS. (LAS TENDENCIAS DEL DERECHO DE SOCIEDADES EN APOYO A LA PYME)*
}

\section{EDUARDO JEQUIER LEHUEDÉ ${ }^{\star *}$}

RESUMEN: La presente investigación trata sobre la regulación de la sociedad anónima de garantía recíproca en el derecho chileno de sociedades, incorporada al ordenamiento jurídico nacional mediante la Ley $\mathrm{N}^{\circ}$ 20.179 , de 20 de junio de 2007. Se analiza el origen, naturaleza y fines de esta nueva figura societaria, abordando en forma sistemática los diversos problemas que plantea su categorización como sociedad anónima y la participación del Estado de Chile, a través de sus órganos administrativos autorizados, en la implementación y consolidación de este mecanismo de apoyo financiero a la micro, pequeña y mediana empresa.

PALABRAS CLAVE: Sociedad anónima - sociedad de garantía recíproca - pequeńa y mediana empresa- financiamiento - afianzamiento - reafianzamiento - intermediación financiera - Programas Corfo.

\section{BUSINESS CORPORATION OF MUTUAL GUARANTEE IN CHILE, CLARIFICATIONS AND PROPOSALS FOR A NEW SYSTEM OF WARRANTIES. (THE TRENDS OF COMPANY LAW IN SUPPORT TO SMES)}

ABSTRACT: This research deals with the regulation of the business corporation of mutual guarantee in the chilean law corporation, incorporated into national law by law No 20,179 of June 20 th , 2007. It is

\footnotetext{
* Esta investigación se origina en la ponencia presentada por el autor en las Segundas Jornadas de Derecho Comercial, realizadas en octubre de 2011 en la Facultad de Derecho de la Universidad Diego Portales.

Fecha de recepción: 24 de enero de 2012.

Fecha de aceptación: 15 de mayo de 2012

** Doctor en Derecho, Universidad de Valencia (ESPAÑA). Mg. en Derecho de la Empresa, P. U. Católica de Chile. Profesor de Derecho Comercial, Universidad de los Andes (CHILE). Profesor de Derecho Comercial y Derecho Económico, Universidad Católica del Norte, sede Coquimbo. Correo electrónico: ejequier@jequier.cl
} 
analyzed the origin, nature and purpose of this new form of company, addressing systematically the various problems raised by its categorization as a corporation and the participation of the state of Chile, through its authorized administrative bodies in the implementation and consolidation of this mechanism of financial support to micro, small and medium enterprises.

KEY WORDS: Business corporation - mutual guarantee - small and medium enterprises (Smes) - financing

\section{INTRODUCCIÓN}

Con fecha 20 de junio de 2007 se publicó en el Diario Oficial la Ley $N^{\circ} 20.179$, que "Establece un marco legal para la constitución y operación de Sociedades de Garantía Reciproca”-en adelante LSGR-.

La referida ley, fruto de un largo proceso legislativo iniciado en agosto del ańo $2004^{1}$, tuvo por motor y punto de partida la constatación -acaso evidente- de la compleja realidad que presenta la pequeña y mediana empresa -Pyme- en Chile, cautiva de y entrampada en un sistema de financiamiento tradicional bien surtido de trabas y obstáculos al emprendimiento innovador.

La conveniencia de recoger entonces en Chile la experiencia de otros países en materia de apoyo a la Pyme, principalmente europeos y algunos sudamericanos como Venezuela ${ }^{2}$ y Argentina ${ }^{3}$, llevaron al ejecutivo a plantear la necesidad de incorporar al sistema crediticio interno un nuevo actor que si bien no formaría parte del sector financiero tradicional, vendría a complementar no obstante la función de este último por la vía de facilitar el flujo del crédito hacia la pequeña y mediana empresa.

La idea, que de novedosa no tenía mucho al menos en el ámbito comparado, consistía esencialmente en estimular y flexibilizar el mecanismo de acceso al crédito de estas empresas sin alterar, sin embargo, las bases estructurales de oferta y demanda que modelan el funcionamiento del mercado crediticio. De lo que se trataba era de incorporar finalmente a la Pyme al club de las empresas consideradas como elegibles de cara al financiamiento de la banca y de las instituciones financieras en general, lo que implicaba mejorar sustancialmente por ende la cualificación de las primeras en cuanto tales sujetos de crédito.

Boletín No 3627-03, disponible en http://www.bcn.cl/histley/lfs/hdl-20179/HL20179.pdf Las SGR en Venezuela están reguladas en el Decreto con Rango y Fuerza de Ley $\mathrm{N}^{\circ} 251$, publicado en el Diario Oficial el 11 de agosto de 1999.

3 Reguladas en la Ley $\mathrm{N}^{\circ}$ 24.467, del 23 de marzo de 1995. 
La fórmula, con todo, no consistía en crear una figura nueva que viniese a competir con dichas instituciones en el otorgamiento del crédito, sino por el contrario, su objetivo era complementar la función económica de estas últimas y dinamizar con ello el sistema de asignación de recursos por una vía indirecta de intermediación financiera, orientada fundamentalmente al mejoramiento sustancial de la estructura de garantías de la Pyme para acceder a tales recursos. Así lo deja en claro el Mensaje enviado por el ejecutivo al Congreso Nacional, que si bien no incorpora al texto del proyecto de ley una concreta definición de lo que debe entenderse para estos efectos por pequeńa y mediana empresa ${ }^{4}$, destaca precisamente

4 En Chile, al igual que en el ámbito comparado, la regulación y las políticas de apoyo a la Pyme constituyen un aspecto esencialmente dinámico y de permanente actualidad. No existe por lo mismo un criterio único para definir a la Pyme, lo que lo transforma en un concepto esencialmente amplio de cara a las múltiples variables económicas que lo informan. En Chile, la Ley $\mathrm{N}^{\circ} 20.416$ (D.O. de 3 de febrero de 2010), que "Fija normas especiales para las empresas de menor tamaño", define a la micro, pequeńa y mediana empresa en su artículo segundo, tomando como base para ello el monto de sus ingresos anuales. Seńala esta norma:

"Articulo Segundo.- Sujeto. Para los efectos de esta ley, se entenderá por empresas de menor tamaño las microempresas, pequeñas empresas y medianas empresas.

Son microempresas aquellas empresas cuyos ingresos anuales por ventas y servicios y otras actividades del giro no hayan superado las 2.400 unidades de fomento en el último año calendario; pequeñas empresas, aquellas cuyos ingresos anuales por ventas, servicios y otras actividades del giro sean superiores a 2.400 unidades de fomento y no exceden de 25.000 unidades de fomento en el último año calendario, y medianas empresas, aquellas cuyos ingresos anuales por ventas, servicios y otras actividades del giro sean superiores a 25.000 unidades de fomento y no exceden las 100.000 unidades de fomento en el último año calendario".

La Corporación de Fomento de la Producción -CORFO- por su parte, en el marco de su "Programa de Linea de Crédito a Fondos de Garantía - IGR III" (Resol. Ex. de 31 de agosto de 2011, Comité Ejecutivo de Créditos, que aprueba las nuevas normas por la que se rige el seńalado Programa), restringe el universo de las empresas Pyme "elegibles" o beneficiarias del afianzamiento y reafianzamiento dado por las SGR y los Fondos de Inversión Privados regulados en dicho Programa, respectivamente, seńalando en el apartado $5^{\circ}$ inc. $3^{\circ}$ del mismo: "En todo caso, las ventas del año anterior o de los últimos doce meses, de las empresas beneficiarias de las garantias constituidas por el Fondo, no podrán ser superiores del equivalente a UF 150.000, que para efectos del presente programa se entienden como micro, pequeñas $y$ medianas empresas, a la fecha de la emisión del certificado de Fianza respectivo por el Fondo. Se incluyen como empresas beneficiarias a las que estén afectas al sistema de renta presunta, pero en este caso las IGR serán responsables de recabar la información necesaria para determinar que el nivel de ventas es inferior al limite establecido en este párrafo".

En el ámbito del Derecho comunitario europeo, por último, la Recomendación de la Comisión 96/280/CE, de 3 de abril de 1996, incluye también una serie de variables para definir a la Pyme, seńalando al respecto en el art. $2^{\circ}$, Título I de su Anexo:

"Articulo 2. Los efectivos y limites financieros que definen las categorias de empresas.

1. La categoría de microempresas, pequeñas y medianas empresas (PYME) está constituida por las empresas que ocupan a menos de 250 personas y cuyo volumen de negocios anual no excede de 50 millones de euros o cuyo balance general anual no excede de 43 millones de euros.

2. En la categoría de las PYME, se define a una pequeña empresa como una empresa que ocupa a menos de 50 personas y cuyo volumen de negocios anual o cuyo balance general anual no supera los 10 millones de euros.

3. En la categoria de las PYME, se define a una microempresa como una empresa que ocupa a 
que "Uno de los problemas que se ha podido percibir a lo largo de los últimos años de ejecución de programas de apoyo financiero y técnico dirigidos a la mediana y pequeña empresa, es la carencia de un acceso expedito al financiamiento requerido para sus operaciones", agregando luego que "Una de las razones de ello es la escasa flexibilidad que posee el sistema de constitución, administración y cancelación o alzamiento de garantías (...)" 5 .

El presente estudio pretende abordar entonces las principales características de la SGR como sociedad de capital y, más concretamente, los problemas que enfrenta en cuanto herramienta jurídico-económica de financiamiento de la Pyme en Chile. Para ello, se analizará en primer término su concreta naturaleza jurídica como sociedad de capital y sus particulares características en cuanto entidad intermediadora en el mercado financiero, para continuar luego, en una segunda parte, con una revisión de las iniciativas de apoyo indirecto a la Pyme que ha implementado el Estado a través de CORFO, tomando como vehículo precisamente esta novedosa figura del derecho chileno de sociedades.

\section{1) Cuestiones PReVias. El PRoblema del FinANCIAMiento DE la PyMe EN CHILE}

Nadie discute en la actualidad la importancia que representa el sector de la Pyme como motor de desarrollo económico y creación de empleo ${ }^{6}$. Pese a ello, la misma certeza existe sin embargo al momento de reconocer las dificultades que deben enfrentar dichas empresas, tanto en Chile como en la mayoría de los países, a consecuencia del insuficiente acceso a los productos y servicios financieros que les resultan esenciales para llevar a cabo sus proyectos y emprendimientos. Según encuestas recientes ${ }^{7}$, en efecto, en Chile un $98,9 \%$ de las empresas califica como Pyme, las

menos de 10 personas y cuyo volumen de negocios anual o cuyo balance general anual no supera los 2 millones de euros". Disponible en http://eur-lex.europa.eu/LexUriServ/LexUriServ.do?u ri=OJ:L:2003:124:0036:0041:es:PDF

(consultada el 23 de enero de 2012).

5 Mensaje Presidencial a la H. Cámara de Diputados, de 10 de agosto de 2004, Boletín No 3627-03, disponible en http://www.bcn.cl/histley/lfs/hdl-20179/HL20179.pdf.

6 Según un estudio realizado por la Biblioteca del Congreso Nacional, en Chile la Pyme genera el $80 \%$ del empleo, del cual una buena parte no cuenta sin embargo con calificación ("Radiografía de las Pymes 2006", de 29 de agosto de 2006, disponible en http://www.bcn.cl/carpeta_temas/temas_ portada.2006-08-08.7810152165).

7 "Primera Encuesta Longitudinal de Empresas (ELE): Resultados Seleccionados por Género"; Subsecretaría de Economía y Empresas de Menor Tamaño.

Disponible en http://www.observatorioempresas.gob.cl/LinkClick.aspx?fileticket $=\mathrm{R} 5 \mathrm{aQXxxh} 7 \mathrm{~d} 0 \% 3 \mathrm{D} \&$ tabid $=90$

(consultada el 26 de septiembre de 2011). 
que a su turno proporcionan espacio para el 60\% del empleo a nivel nacional. Por contrapartida sin embargo, su contribución a las ventas es comparativamente muy baja respecto de otros países, pues no supera el $15 \%$ debido, en gran medida $-y$ sin perjuicio de lo que se dirá a continuación - a la insuficiencia de capital de trabajo derivada de la falta de garantías. En este sentido, en fin, los datos recogidos por el Banco Mundial indican precisamente que un gran porcentaje de los créditos solicitados por las micro, pequeńas y medianas empresas son rechazados por falta de garantías ${ }^{8}$, ya sea porque dichas empresas no las tienen simplemente o, peor aún, porque teniéndolas ellas se encuentran inmovilizadas del todo, cautivas de un determinado crédito hasta su completa extinción.

Se trata, por ende, de una vistosa falla del mercado financiero que impacta de lleno en las expectativas de crecimiento de la Pyme, originada fundamentalmente por las siguientes razones:

a) Una variable relevante en este sentido, que permite explicar en parte este complejo fenómeno, radica en las deficiencias que presenta la Pyme en cuanto a la creación, manejo y entrega de información financiera de calidad, lo que genera problemas de asimetría en la información que repercuten derechamente en el costo y en los plazos de los créditos para este segmento? ${ }^{\text {. }}$

El deudor maneja en efecto antecedentes estratégicos y de gestión del negocio que el financista no tiene, de manera que la entrega opor-

8 Economía y Negocios, de 3 de abril de 2008. Disponible en http://www.economiaynegocios.cl/noticias/noticias.asp? id $=44776$

(consultada el 26 de septiembre de 2011). Al respecto puede consultarse también a Goldberg, Mike y Palladini, Eric (2008) "Chile: A Strategy to Promote Innovative Small and Medium Enterprises", en Policy Research Working Paper, $N^{\circ}$ 4.518, Banco Mundial, p. 12.

9 Las asimetrías de información se explican fundamentalmente por la presencia -normalmente concurrente- de dos factores fundamentales, conocidos en la doctrina económica como el problema de selección adversa y el fenómeno del riesgo moral o moral hazard. El primero -dice YáŃEZ- genera asimetrías de información "porque los malos deudores perjudican a los buenos, es decir la tasa de interés que deben pagar estos últimos debe compensar las pérdidas que generan las empresas que no llegan a cumplir sus obligaciones, así cuando un banco aumenta la tasa de interés aleja o saca del mercado a los buenos deudores y se podría quedar con malos deudores. Un mecanismo de defensa que tienen los acreedores frente a la selección adversa es la exigencia de garantías, pues con ello se cubren del riesgo de no pago. En cuanto al riesgo moral, se trata de un fenómeno asociado principalmente a la conducta que asumen los deudores una vez obtenido el crédito respectivo. En tales casos, seńala el mismo autor, "la empresa tiene incentivos a tomar mayores riesgos, pues las posibles pérdidas las asumen tanto el financista como la empresa, mientras las eventuales ganancias, en su mayoría son para ella. La consecuencia natural de este hecho, es que se cobre una mayor tasa de interés a todos los deudores de un mismo tipo, como también aumentar las garantías exigidas". YáŃEZ, Álvaro A. (2007) "Supervisión de las Sociedades de Garantía Recíproca (SGR) en Chile”, en Serie Técnica de Estudios $\mathrm{N}^{\circ}$ 09, Santiago: Superintendencia de Bancos e Instituciones Financieras, p. 9. 
tuna, veraz y completa de esta información resulta vital para la materialización de la operación de crédito. Al no darse ese flujo informativo -o al menos no con los estándares mínimos de fiabilidad que espera el acreedor-, el crédito que eventualmente se otorgue se hace costoso e incluso inadecuado de cara a los plazos de maduración que requieren las inversiones respectivas, con el posible fracaso del emprendimiento Pyme en su globalidad.

b) Otro factor relevante, vinculado al anterior, tiene lugar en la etapa posterior al otorgamiento del crédito a la Pyme, cuando la empresa deudora ha obtenido ya los recursos solicitados a su acreedor.

Nos referimos en concreto al conflicto de intereses que se genera eventualmente de cara al destino real que el deudor le asigna a los recursos obtenidos, el que muchas veces no coincide con el que tuvo a la vista el acreedor al otorgar el crédito. Dicho en otros términos, el deudor, para maximizar sus utilidades, puede optar por no destinar los fondos provenientes del crédito a las inversiones comprometidas al momento de solicitarlo, desviándolos por ende a otros fines que son del todo desconocidos por el acreedor. Como apunta Martínez ${ }^{10}$, en fin, en estos casos "se produce una desviación de recursos que representa, en la práctica, un desplazamiento sobre el acreedor del volumen de riesgo adicional sobrevenido moral", lo que repercute sin duda en un crédito más caro y a la larga más escaso.

c) Las condiciones de contratación impuestas a las Pyme por los denominados "grandes clientes", entendiéndose por tales al propio Estado, a las grandes tiendas, los supermercados y la gran industria. Todos ellos, en mayor o menor medida, pueden verse tentados a abusar de su posición de poder frente a la Pyme por la vía de la fijación unilateral de condiciones de pago, sistemas de descuentos y multas, etc., lo que impacta directamente en el potencial de consolidación y desarrollo de este sector ${ }^{11}$.

d) Los bancos e instituciones financieras por su parte, pese al papel fundamental que juegan como vehículo de financiación de las Pymes -que por regla general no tienen acceso al mercado de valores como fuente alternativa-, no cuentan tampoco con mecanismos de análisis de riesgo y de asignación de crédito que sean apropiados para el grado de desarrollo y para la envergadura de estas empresas, lo que obstaculiza sus posibilidades de crecimiento.

Dichas instituciones, en efecto, tienden a utilizar políticas y procedimientos corporativos estandarizados de análisis crediticio, regidos

10 Martínez Mulero, Víctor (2005) El control de los administradores y la impugnación de sus acuerdos. Madrid: La Ley, p. 16.

11 Sobre este aspecto puede consultarse el informe de la Asociación de Exportadores de Manufacturas y Servicios A.G. -ASEXMA-, "Análisis del impacto en las Pyme frente al actual escenario de garantías CORFO y programas SGR", agosto de 2011, p. 5. 
además por normas que apuntan a dar seguridad y solvencia al sistema financiero y que restringen, por lo mismo, su autonomía en cuanto a la determinación de los límites individuales de crédito ${ }^{12}$. Tal circunstancia, que repercute nuevamente en el acceso al crédito Pyme, genera al mismo tiempo una notoria desproporción en el poder de negociación entre el acreedor y el deudor con garantías insuficientes, lo que influye muchas veces en una merma de la calidad del crédito involucrado.

Todo lo anterior, en síntesis, explica que el porcentaje de empresas Pyme en Chile, que utilizan efectivamente el crédito bancario para financiar sus proyectos de inversión, sea sustancialmente menor que el que presentan las grandes empresas. En el siguiente cuadro se muestra en términos estadísticos lo que se acaba de señalar ${ }^{13}$ :

\section{PORCENTAJE DE EMPRESAS QUE UTILIZAN CRÉDITO BANCARIO EN CHILE Y PAÎ́SES SELECCIONADOS}

\section{País/Tamaño de empresa}

Argentina

Brasil

Chile

México

Espańa
Total

6,9

48,4

29,1

2,6

32,6
Pequeña

3,3

22,5

16

1,9

26,2
Mediana

8,5

48,8

23,5

2,6

38,7
Grande

14

68,4

62,8

12,1

47,7

Coincidente con lo anterior, el cuadro siguiente muestra que el mayor porcentaje de inversiones empresariales en Chile, financiadas por la banca, se encuentra también en el segmento de la gran empresa ${ }^{14}$ :

12 Sin perjuicio de los resguardos que imponen en este sentido los acuerdos de Basilea, el artículo $84 \mathrm{~N}^{\circ} 1$ de la Ley General de Bancos (DFL N³, de 19 de diciembre de 1997) fija como límite para el otorgamiento de créditos a una misma persona, natural o jurídica, un monto no superior al $10 \%$ de su patrimonio efectivo, ampliable al $15 \%$ cuando se trata del financiamiento de obras fiscales del sistema de concesiones públicas, y al $30 \%$ si lo que excede del $10 \%$ antes seńalado corresponde a créditos caucionados por garantías sobre bienes corporales muebles o inmuebles de un valor igual o superior a dicho exceso.

13 Banco Mundial, Enterprise Surveys, www.enterprisesurveys.org. Encuestas realizadas entre 2006 y 2009 sobre muestras de 1.000-1.500 empresas. Pequeńa empresa: hasta 20 empleados, Mediana: 20-99 empleados, Grande: 100 o más empleados. 


\section{PORCENTAJE DE INVERSIONES EMPRESARIAS FINANCIADAS CON CRÉDITO BANCARIO EN CHILE Y PAÍSES SELECCIONADOS}

$\begin{array}{lcccc}\begin{array}{l}\text { País/Tamaño } \\ \text { de empresa }\end{array} & \text { Total } & \text { Pequeña } & \text { Mediana } & \text { Grande } \\ \text { Argentina } & 5,4 & 1,6 & 8,9 & 7,5 \\ \text { Brasil } & 33,6 & 15,1 & 32,7 & 49,7 \\ \text { Chile } & \mathbf{3 6 , 1} & \mathbf{3 3 , 9} & \mathbf{1 6 , 9} & \mathbf{5 9 , 8} \\ \text { México } & 6,8 & 5,6 & 4,2 & 23,7 \\ \text { Espańa } & 21,9 & 20 & 24,6 & 25\end{array}$

Por último, las dificultades de acceso al financiamiento constituyen un factor determinante para el desarrollo de la Pyme en Chile, que el empresariado de dicho segmento destaca como un obstáculo de especial entidad $^{15}$ :

\section{PORCENTAJE DE EMPRESAS QUE IDENTIFICAN EL ACCESO AL CRÉ- DITO COMO UN PROBLEMA SERIO PARA SU CRECIMIENTO EN CHILE Y PAIISES SELECCIONADOS}

$\begin{array}{lcccc}\begin{array}{l}\text { País/Tamańo } \\ \text { de empresa }\end{array} & \text { Total } & \text { Pequeńa } & \text { Mediana } & \text { Grande } \\ \text { Argentina } & 38,5 & 40 & 38,5 & 34 \\ \text { Brasil } & 55,5 & 50,6 & 55,7 & 61,6 \\ \text { Chile } & \mathbf{2 0 , 4} & \mathbf{3 4 , 9} & \mathbf{1 1} & \mathbf{5 , 3} \\ \text { México } & 15,1 & 17,2 & 8,9 & 13,8 \\ \text { Espańa } & 13,3 & 13,9 & 13,5 & 10,9\end{array}$

En síntesis, y para concluir con este análisis preliminar, para la Pyme el alto costo del crédito, cuando se tiene acceso a él, constituye un desincentivo para nuevos proyectos y una pesada carga financiera para aquellos emprendimientos que, habiendo logrado algún grado de madurez, dependen todavía del financiamiento externo.

El sistema financiero, por su parte, asume que los riesgos involucrados en este sector empresarial son también altos, lo que repercute en el

15 Banco Mundial. 
incremento de las tasas y en la reducción de los plazos, sin perjuicio de los altos costos de transacción que se suman a dichas operaciones.

Este fenómeno entonces, que constituye un factor crítico de cara a la obtención de créditos de largo plazo y bajo costo, repercute finalmente en una reducción sustancial de los márgenes de ganancias de las Pyme al limitar sus ventas - por un lado- y encarecer sus inversiones en tecnología y capacitación -por el otro-, con el consiguiente desincentivo para los pequeños y medianos emprendedores a la hora de crear nuevas empresas. En comparación con las grandes compañías, en fin, las Pyme tienen sin duda mayores dificultades para acceder a la financiación bancaria, lo que se ve agravado por niveles de endeudamiento por ventas sustancialmente mayores a los que presenta la empresa de mayor tamańo, que como contrapartida accede a préstamos menos costosos.

\section{2) LA SOCIEDAD DE GARANTÍA RECíPROCA EN LA LEGISLACIÓN CHI- LENA}

La Ley $\mathrm{N}^{\circ}$ 20.179, para mejorar la tradicional estructura de garantías de la Pyme en Chile y enfrentar por esa vía el fenómeno descrito supra, crea en su Título I la nueva figura de las denominadas "Instituciones de Garantía Reciproca" -IGR-, innovando sustancialmente respecto de los modelos monistas que han adoptado aquellos países con mayor experiencia en esta materia.

La ley chilena, en efecto, reconoce en su art. $1^{\circ}$ dos tipos de IGR, ambas de carácter esencialmente privado aunque de naturaleza y orientación funcional distintas: las Sociedades Anónimas de Garantía Recíproca -SGR-, a la que dedicaremos el presente estudio; y las Cooperativas de Garantía Recíproca -CGR-, constituidas con sujeción a las normas aplicables a las cooperativas de ahorro y crédito para desarrollar el mismo giro de las SGR, previa autorización de del Departamento de Cooperativas del Departamento de Economía, Fomento y Reconstrucción.

\section{1.) LAS SOCIEDADES ANÓNIMAS DE GARANTÍa RECÍPROCA. DEL SIS- TEMA MUTUALISTA PURO A LA EXTERNALIZACIÓN DE GARANTÍAS PERSONALES}

En primer término, en su art. $1^{\circ}$, inc. $1^{\circ}$, la ley autoriza el establecimiento de las denominadas Sociedades Anónimas de Garantía Recíproca o "S.A.G.R.", las que se rigen por las normas de la Ley $\mathrm{N}^{\circ} 18.046$ en todo aquello que no se encuentre expresamente regulado por la Ley $\mathrm{N}^{\circ} 20.179$.

En lo que a estas sociedades concierne entonces, y como se acaba de adelantar, la Ley $\mathrm{N}^{\circ} 20.179$ marca una clara diferencia respecto del diseńo 
implementado en aquellas legislaciones comparadas que le sirvieron de modelo inicial, ampliando sustancialmente el ámbito de desempeńo de tales entidades.

En España ${ }^{16}$, en efecto, la SGR constituye un tipo especial de sociedad sin fines de lucro, que se rige principalmente por las normas de las sociedades anónimas - sin serlo- y que se caracteriza además por presentar un marcado carácter mutualista de cara a los derechos y obligaciones de sus socios. Se trata, en concreto, de un tipo societario específico y autónomo, un híbrido entre la sociedad capitalista y la sociedad mutualista integrado por pequeńos y medianos empresarios que se asocian entre sí para mejorar sus expectativas de financiamiento a través de garantías o avales que les otorga la propia sociedad, sin posibilidad de que accedan a tales beneficios terceros extrańos a ella. Como señalan Uría y Menéndez ${ }^{17}$, en fin, la SGR es considerada en Espańa como un tipo social híbrido y autónomo, creada con la finalidad de servir exclusivamente como instrumento de financiación a sus socios y considerada, por lo mismo, como una entidad financiera sometida al registro, control e inspección del Banco de España (arts. 1 y 66 de la Ley 1/1994). Junto a ellas, además, la misma ley contempla las denominadas "sociedades de reafianzamiento" 18 , a través de las cuales la administración pública refuerza financieramente el funcionamiento del sistema referido mediante el apalancamiento de las SGR, las que son reafianzadas precisamente por el Estado en el otorgamiento de las garantías personales a sus socios, que podrán ser "partícipes" o "protectores"19.

16 Las SGR fueron creadas mediante Real Decreto-ley 15/1977, de 25 de febrero, siguiendo a su turno el modelo francés aunque con algunas variantes respecto de la estructura del denominado "fondo de garantía" (sobre el origen y finalidad del Fondo de Garantía de la SGR puede consultarse a Bueso Guillén, Pedro José (2000) "El fondo de provisiones técnicas de la sociedad de garantía recíproca", en Revista de Derecho de sociedades, $\mathrm{N}^{\circ} 15$, pp. 159-171). Posteriormente el Real Decreto 1885/1978, de 26 de julio, reguló el régimen jurídico, tributario y financiero de dichas sociedades, hasta que fue derogado por la Ley $1 / 1994$, de 11 de marzo, reglamentada por el Real Decreto 2345/1996, de 8 de noviembre, que establecen el marco legal vigente. El origen de tales sociedades se encuentra sin embargo en el derecho francés, que pocos ańos antes había creado las denominadas Sociedades de Garantía Mutua. Uría, Rodrigo (2001) Derecho Mercantil, 28 edición. Madrid: Marcial Pons, p. 591.

17 Uría, Rodrigo y Menéndez, Aurelio (1999) Curso de Derecho Mercantil, Tomo I. Madrid: Civitas, p. 1303.

18 Las sociedades de reafianzamiento, contempladas en la Ley $1 / 1994$, se encuentran reguladas además en el Real Decreto 1644/1997, de 31 de octubre, referido a las normas de autorización administrativa y requisitos de solvencia de tales entidades. Deben constituirse como sociedades anónimas participadas por la administración pública, y son consideradas como entidades financieras para todos los efectos.

19 Según el art. 6 de la Ley 1/1994, son socios partícipes las personas naturales o jurídicas del ámbito de las Pyme, que podrán solicitar la garantía de la sociedad; y protectores los que no reúnan tal condición de Pyme y que, por lo mismo, no podrán ser beneficiados por garantías personales otorgadas por la sociedad. La participación de estos últimos en 
Pues bien, el modelo recién expuesto fue el que tuvo a la vista precisamente el proyecto de ley enviado inicialmente por el Ejecutivo al Congreso Nacional, referido supra, en donde se replicaban sustancialmente las bases estructurales del señalado mecanismo aunque adoptando, para dicho fin, el tipo societario de la sociedad anónima. Como lo aclaraba concretamente el Mensaje del Ejecutivo, en efecto, "El modelo predominante de operación de este tipo de sociedades establece una identidad entre (i) quienes aportan el capital de garantía, (ii) quienes gestionan y otorgan las cauciones, y (iii) entre quienes son los beneficiarios de las mismas"20, lo que delineaba por ende los fundamentos de un esquema con claras pautas mutualistas, sin posibilidad alguna de beneficiar a terceros que no fuesen miembros o socios de las entidades referidas. Las sociedades de garantía recíproca, según esto, debían constituirse únicamente en base a gremios o sectores productivos determinados, de manera que permitir que los recursos de tales sociedades beneficiaran también a terceros podía constituir una limitación al acceso a la garantía por parte de los socios respectivos ${ }^{21}$.

Durante el trámite legislativo, sin embargo, el legislador innovó sustancialmente respecto de la idea original, ampliando el ámbito operativo de las sociedades de garantía recíproca al permitir que sus beneficiarios no fuesen exclusivamente sus propios socios o accionistas, sino también terceros ajenos a la sociedad. Tal iniciativa, que constituye un significativo avance de cara al financiamiento de la Pyme en general, se refleja expresamente en el art. $2^{\circ}$, letra a), de la Ley $\mathrm{N}^{\circ} 20.179$, que define precisamente a los beneficiarios de las SGR sin las limitaciones subjetivas que contemplaba el texto original ${ }^{22}$. Según la norma citada, en fin, serán beneficiarios de las SGR "las personas naturales o jurídicas que de conformidad al estatuto de la Institución pueden optar a ser financiados por esta para caucionar sus obligaciones (... $)^{\prime 23}$, entregando de tal forma la iniciativa en esta materia a la autonomía de la voluntad de los accionistas.

el capital, directa o indirecta, no podrá exceder en conjunto del $50 \%$ de la cifra mínima fijada para el capital social, lo que constituye para estos socios una alternativa de inversión rentable que compite con otras que el mercado pueda ofrecer en un momento dado.

20 Mensaje Presidencial, p. 6.

21 Así lo explicaba el abogado asesor del Ministerio de Justicia en la Comisión Especial Pymes.

22 Según el art. $2^{\circ}$ letra a) del proyecto, se entendía por "Accionistas beneficiarios o beneficiarios: aquellas personas naturales o juridicas que participan en el capital social y que pueden optar por ser afianzados por la sociedad para caucionar las obligaciones que adquieran, de conformidad con la presente ley", excluyendo por ende a terceros ajenos a la sociedad.

23 La redacción de esta norma tiene su origen en una indicación efectuada en la Comisión Especial Pymes por los diputados José Antonio Galilea, González, Montes, Venegas y Urrutia, la que recogió a su turno las observaciones del asesor del Ministerio de 
En síntesis, y a diferencia del modelo mutualista ya mencionado, la SGR en Chile no es únicamente una sociedad de empresarios de determinado gremio o sector de actividad económica, que se agrupan asociativamente con miras a obtener el respaldo de la entidad de cara al financiamiento indirecto de los negocios y operaciones propias. Más que eso, la SGR puede constituirse también -exclusivamente incluso- por accionistas inversores -partícipes en la nomenclatura española- cuya finalidad será obtener únicamente una rentabilidad lícita con ocasión del afianzamiento y asesoría de terceros beneficiarios, sin que tales socios lleguen jamás a requerir en su beneficio el otorgamiento del aval o fianza de la sociedad.

\section{2.) PRINCIPAles CaraCterísticas DE LA SGR}

Si bien las sociedades de garantía recíproca se rigen por las normas de la Ley $\mathrm{N}^{\circ} 18.046$, lo cierto es que la Ley $\mathrm{N}^{\circ} 20.179$ establece para ellas una serie de requisitos especiales que las distinguen claramente de una sociedad anónima cerrada común. En estricto rigor, con todo, no puede hablarse aquí de una sociedad anónima abierta o especial, según el concepto que entrega al respecto el art. $2^{\circ}$ de la LSA.

\subsection{1.) La SGR como sociedad anónima}

Al no existir requisitos especiales en cuanto al número mínimo de accionistas que puede tener una SGR, sean personas naturales y/o jurídicas, necesariamente debe concluirse que estas pueden constituirse como sociedades anónimas cerradas o abiertas. Lo dicho, claro está, es sin perjuicio de las normas especiales aplicables a este subtipo societario, que se analizarán más adelante. No es sin embargo una sociedad anónima especial, como lo ha sostenido algún autor ${ }^{24}$, pues su constitución válida no

Economía, Fomento y Reconstrucción, don Cristián Palma. Según este "la apertura de la Sociedad de Garantía Recíproca hacia afianzados que no tengan la calidad de accionistas pretende, en primer lugar, permitir la viabilidad en el largo plazo de este tipo de sociedades. Para ello, se requiere que participen un mayor número de personas, siempre que reúnan las características que definan los estatutos de la propia sociedad. En segundo lugar (...) los pequeńos y medianos empresarios enfrentan serias dificultades para acceder al capital. De ahí entonces que exigirles adicionalmente que destinen parte de su capital propio a la constitución de una Sociedad de Garantía Recíproca sería un despropósito”. especial de carácter mercantil, constituida por pequeńos y medianos empresarios (individuales o colectivos), con capital variable y cuyo objeto exclusivo consiste en prestar garantía por aval a favor de sus accionistas beneficiarios para las operaciones que estos 
queda condicionada al cumplimiento previo de los requisitos establecidos en el Título XIII de la LSA.

Pese a lo anterior, y si bien no existe duda posible en cuanto a la naturaleza de sociedad anónima que tiene en Chile la SGR -pues es la propia ley la que lo dice así-, nos parece sin embargo que su diseńo legal presenta aspectos de difícil encasillamiento en el esquema de una sociedad anónima en cuanto sociedad de capital.

La sociedad de capital, en efecto, desde sus mismos orígenes en las compañías de comercio privilegiadas del siglo XIX, ha mostrado características muy distintas a las de la tradicional sociedad mercantil. Concebidas para el logro de objetivos económicos determinados, las sociedades de capital abandonan precisamente la condición personalista de las restantes sociedades comerciales para transformarse en un vehículo empresarial con clara vocación patrimonialista, en donde el capital -como apunta Hierro ${ }^{25}$ - pasa a constituir "el elemento definitorio por excelencia de la compañía de comercio, que la convierte en la primera institución mercantil que logra convertir el capital en mercader, anulando la base personalista de la compañía mercantil general al sustituirla por la base estrictamente capitalista por la que hasta hoy se conoce a la sociedad anónima”. Podemos afirmar entonces con RIPERT ${ }^{26}$ que aparte del nombre común -sociedad- no existe mayor relación ni parentesco entre las sociedades personalistas en nombre colectivo y una sociedad capitalista como la sociedad anónima. Desde luego -dice el mismo autor-, la palabra "socios" no se emplea jamás para designar a los accionistas, pues lo que los vincula a la sociedad no es el contrato social sino la tenencia de un título negociable $^{27}$; a lo que se suma que las sociedades capitalistas tampoco se desenvuelven en consideración a un determinado grupo de socios vinculados entre sí por lazos personales -como ocurre en las mencionadas sociedades personalistas-, sino con miras a la conformación de un patrimonio orientado a la materialización de un determinado emprendimiento con fines

realicen dentro del tráfico de las empresas de que sean titulares, y quien además los asesora con respecto a las formas más adecuadas de financiación para sus respectivas operaciones" (Silva Walbaum, Adolfo (2008) "Normas orgánicas y funcionales de la sociedad de garantía recíproca chilena". Trabajo presentado en el marco del XIII Foro iberoamericano de sistemas de garantía y financiamiento para las micro, pequeñas y medianas empresas, Valparaíso, Chile p. 51. Disponible en http://www.redegarantias.com/archivos/web/ficheros/2010/xiii_foro_ iberoamericano_de_garantias.pdf (consultado el 18 de enero de 2012).

25 Hierro Anibarro, Santiago (1998). El origen de la sociedad anónima en España. Madrid: Tecnos, p. 302.

26 Ripert, Georges (1950). Aspectos jurídicos del capitalismo moderno, traducción por José Quero Molares. Buenos Aires: Ediciones Jurídicas Europa-América, p. 107.

27 RIPERT, Georges (1954). Tratado Elemental de Derecho Comercial, Vol. II, Paris: Lib. Generale de Droit de Jurisprudence, p. 305. 
de lucro y en donde la persona del accionista, por lo mismo, adquiere un carácter esencialmente fungible.

Con todo, lo dicho supra constituye un planteamiento cuya incardinación con el modelo chileno de SGRs presenta algunos ripios dogmáticos manifiestos, de compleja armonización con la concepción patrimonialista de la sociedad de capital.

En primer término, la particular fisonomía que el legislador le asigna a la SGR implica que esta puede constituirse con una vocación estrictamente mutualista, para afianzar como ya se dijo las obligaciones contraídas por sus accionistas en el ejercicio de sus actividades empresariales, productivas, profesionales o comerciales (art. 1 inc. $2^{\circ}$ y art. $3 . \mathrm{a}$ de la LSGR). En tales casos, pues, las sociedades de garantía recíproca no presentan mayores diferencias en cuanto al capital social y a la responsabilidad de los socios por las deudas sociales; pero en lo que se refiere a los derechos de los socios predomina un carácter mutualista que las aleja de la concepción recién apuntada, en donde la persona del accionista constituye un elemento esencialmente fungible de la sociedad de capital ${ }^{28}$.

Por otra parte, aunque relacionado con lo anterior, el art. 5 inciso final de la LSGR seńala que "Los estatutos podrán establecer requisitos para adquirir la calidad de accionistas y de beneficiario", lo que en cierto modo personaliza una sociedad que es despersonalizada por antonomasia. En otros términos, se deja entregada a la autonomía de la voluntad de los accionistas, sin más limitantes que las que surjan de la aplicación de normas jurídicas concretas ${ }^{29}$, la facultad de incorporar al estatuto determinados rasgos subjetivos que puedan servir de pauta para la creación y tutela de vínculos personales entre ellos, que les permitan excluir a priori incluso a

28 Es por ello precisamente que la ley espańola, $N^{\circ} 1 / 1994$ de 11 de marzo, opta por configurar a la SGR como una sociedad especial cuyo estatuto legal se regula de manera completa en la seńalada ley, sin perjuicio de algunas remisiones puntuales a la LSA (contenida actualmente en la Ley de sociedades de capital, Decreto Legislativo $1 / 2010$, de 2 de julio).

29 Así por ejemplo, en principio los bancos no pueden ser accionistas de una SGR dada la prohibición que se establece en el Capítulo 8-10, $\mathrm{N}^{\circ} 4$, inc. $1^{\circ}$, de la Recopilación Actualizada de Normas -RAN- de la SBIF, según el cual "Los bancos no podrán avalar $o$ afianzar obligaciones a favor o de cargo de instituciones financieras establecidas en el país". Por lo demás, los arts. 70 y 70 bis de la Ley General de Bancos, en relación con el Capítulo 11-6 de la RAN, no contemplan la posibilidad de crear una SGR como filial bancaria. Sin embargo, y tal como se planteó durante el trámite legislativo, los bancos podrían participar en una SGR como sociedad de apoyo al giro (art. 74 LGB), lo que requiere en todo caso de una autorización expresa de la SBIF y de la dictación previa de las normas pertinentes en cuanto al porcentaje de participación mínimo o máximo, capital, etc. Al respecto puede verse la discusión en torno a la indicación $\mathrm{N}^{\circ} 8$ presentada por el senador Sr. Vásquez, en la Comisión de Economía del Senado. 
quienes no compartan un determinado perfil, lo que desfigura necesariamente la base patrimonialista de la sociedad anónima"30.

\subsection{2.) En cuanto al objeto social}

Según el art. $1^{\circ}$ de la Ley $\mathrm{N}^{\circ} 20.179$, en relación con el art. 3 de la misma ley, las SGR son sociedades anónimas de giro exclusivo. En consecuencia, su objeto social solo podrá consistir en aquello que la ley permite en la norma recién citada, según pasamos a revisar:

\section{a) El otorgamiento de garantías personales; objetivos directos e indi- rectos}

El art. 3 letra a) de la LSGR señala en primer término que el objeto de la sociedad consistirá "en el otorgamiento de garantías personales a los acreedores de sus beneficiarios, con la finalidad de caucionar obligaciones que ellos contraigan, relacionadas con sus actividades empresariales, productivas, profesionales o comerciales". Tales garantías -aclara la norma en su inciso penúltimo- podrán acceder a obligaciones de dar, hacer o no hacer en que el beneficiario sea el deudor principal, siempre y cuando su fuente u origen se encuentre "dentro del giro de las actividades empresariales, productivas, profesionales o comerciales de este".

Por excepción, la misma norma permite en su inciso final que las SGRs garanticen los actos o contratos mediante los cuales el beneficiario transfiera créditos que posea contra terceros, adquiridos en el ejercicio de sus actividades empresariales, productivas, profesionales o comerciales y de los cuales se deriven obligaciones subsidiarias o solidarias para aquel, "aun cuando el beneficiario no sea deudor principal", lo que constituye una importante herramienta para potenciar además el acceso de la Pyme a otros instrumentos de intermediación financiera como el factoring, en mejores condiciones y a menores $\operatorname{costos}^{31}$.

Por último, una manifestación de especial relevancia en este sentido consiste en la posibilidad que se le reconoce a las SGRs para otorgar

30 Como seńala Puga, en la sociedad anónima "la relación jurídica existe entre el accionista y la sociedad y no entre el accionista y los restantes accionistas". Puga Vial (20 i i), Juan Esteban, La sociedad anónima y otras sociedades por acciones por acciones en el derecho chileno y comparado. Santiago: Editorial Jurídica de Chile, p. 241.

31 Debe advertirse sin embargo que el Programa IGR-III de CORFO exige contragarantías reales como condición para reafianzar obligaciones con cargo al fondo de reafianzamiento, en los términos que se indican en el apartado 4.d) de dicho Programa. En consecuencia, la posibilidad de la SGR para operar con estos derechos personales o créditos $y$, concretamente, para recibirlos como contragarantía en los términos amplios en que se la regula por el art. 11.d) de la LSGR, se ve sin duda limitada por esta vía reglamentaria. 
Certificados de Fianza como garantía técnica en todas aquellas contrataciones que presuponen un proceso de licitación previa para las Pyme, sea pública o privada, asimilándose dichos Certificados a las boletas bancarias de garantía para todos los efectos ${ }^{32}$. En la actualidad por lo mismo, las instituciones públicas están expresamente facultadas para incluir estos Certificados en las compras y contrataciones que efectúen a través de la plataforma de licitaciones del Estado (www.mercadopublico.cl), en reemplazo como se dijo de las boletas bancarias de garantía. Tales instrumentos serán pagaderos a la vista según lo dispone el artículo 68 del Reglamento de la Ley $\mathrm{N}^{\circ} 19.886$ (D.S. N ${ }^{\circ} 250$ de 2004, del Ministerio de Hacienda), y cumplirán las mismas funciones que las restantes garantías aceptadas en estos procesos ${ }^{33}$.

Queda en claro entonces que el objetivo directo de la SGR consiste en el otorgamiento de avales o fianzas a sus beneficiarios, accionistas o terceros, para lo cual estarán liberadas -por evidentes razones operativasde la obligación a que se refiere el art. $57 \mathrm{~N}^{\circ} 5$ de la LSA (art. 3, letra "d"). No podrán, en ningún caso, otorgar créditos directos a sus accionistas o a terceros, y todo acto en contravención a esta prohibición será nulo. Todavía más, los directores y ejecutivos de la sociedad, que hayan intervenido en el otorgamiento de un crédito directo, serán solidariamente responsables de los perjuicios causados con dicha infracción (art. 4 de la LSGR). Tal impedimento, que no se contempla por cierto en la LSA - no al menos en términos de prohibición absoluta-, se explica por cuanto, como se dijo supra, la SGR no está concebida ni facultada por la ley para competir con los bancos e instituciones financieras ni, por ende, para ejercer el giro bancario propiamente tal, en su vertiente tradicional de captación y colocación. Por el contrario, la SGR tiene por objeto cooperar con tales instituciones, flexibilizando -en cuanto garantes cualificados- los estándares crediticios y los procesos de calificación de riesgo por

32 Según el apartado $11^{\circ}$ inc. $3^{\circ}$ del Programa IGR-III de CORFO, “(...) los Certificados de Fianza podrán afianzar hasta el 100\% del monto de la operación, tratándose de Certificados de Fianza emitidos con el objeto de garantizar obligaciones de hacer relacionadas con garantías técnicas, otorgadas a acreedores que no tengan el carácter de intermediarios financieros (...)". Ejemplo reciente de lo seńalado se manifiesta en el artículo 25 inciso final del D.S. $N^{\circ} 174$ (D.O. de 9 de febrero de 2006, Ministerio de Vivienda y Urbanismo), que contiene el Reglamento del Programa Fondo Solidario de Vivienda. En dicha norma se seńala expresamente, que en lugar de la boleta bancaria de garantía a que se refieren los incisos anteriores de la misma norma, "el contratista podrá entregar un Certificado de Fianza emitido por una Institución de Garantía Reciproca regida por la Ley $N^{\circ} 20.179$, clasificada en categoría A (...)".

33 Más información sobre este instrumento puede encontrarse en la "Directiva de Contratación Pública N ${ }^{\circ} 7$ ", de la Dirección de ChileCompra. Disponible en: http:// www.chilecompra.cl/index.php?option=com_phocadownload \&view=category\&id $=12$ \&Itemid=282 (consultado el 12 de octubre de 2011). 
las que estas se rigen, lo que mejora sustancialmente la presentación del deudor Pyme en cuanto sujeto de crédito.

En síntesis, por la vía de su fianza o aval personal la SGR logra romper con la tradicional vinculación y dependencia que existe entre el crédito y la constitución previa de una garantía real a favor del banco o entidad financiera que lo otorga, lo que amén de agilizar los procesos de entrega material de los recursos y mejorar las condiciones del crédito mismo, disminuye significativamente los costes de transacción involucrados en dicha operación y en la constitución de las señaladas garantías, cuando se cuenta con ellas. Del mismo modo, mediante el afianzamiento que otorga la SGR se pretende maximizar la aptitud que tienen los activos del deudor en cuanto bienes de garantía, de manera tal que un mismo bien o derecho pueda servir como garantía para diversas operaciones de afianzamiento. Dicho en otros términos, y a diferencia de lo que ocurre con los acreedores financieros que mantienen cautivos los bienes recibidos en garantía -y con ello a sus deudores Pyme $^{34}$-, el mecanismo de financiamiento indirecto que aplica la ley a través de la SGR permite dividir financieramente las contragarantías reales que estas reciben de los terceros beneficiarios, las que por lo mismo pueden contragarantizar una multiplicidad de operaciones de afianzamiento; tantas cuantas toleren las políticas de garantía y control de riesgo de la sociedad, de cara a los márgenes definidos en tal sentido en los estatutos sociales (art. $5 \mathrm{~N}^{\circ} 2$ de la LSGR).

Por otra parte, aunque relacionado siempre con lo anterior, el mecanismo creado por la ley chilena permite identificar también otros objetivos que, aunque indirectos, son también relevantes y de especial significación. Mediante el afianzamiento a través de la SGR, en efecto, se aspira a liberar paulatinamente las garantías reales que se encuentran inmovilizadas en el sistema financiero, dotándolas por esta vía de una movilidad de la que tradicionalmente han carecido. De esta forma, además, se espera favorecer la competencia en el mercado crediticio, que tendrá por ende un nuevo estímulo para mejorar las condiciones de crédito ofertadas.

Con todo, para que el efecto recién planteado se materialice efectivamente resulta indispensable, al mismo tiempo, que la banca cuente con los incentivos necesarios para reemplazar sus garantías reales por las garantías personales o fianzas otorgadas por la SGR. Tal constatación, pues, aunque evidente, resulta de la mayor relevancia para el éxito de estas enti-

34 Según estudios de la Superintendencia de Bancos e Instituciones Financieras -SBIF-, las empresas de menor tamańo en Chile solo mantienen registro de crédito en una sola institución bancaria. En concreto, la microempresa que accede al crédito bancario lo hace en promedio en un banco, mientras que la Pyme registra un promedio de 1,3 bancos en total. Arriagada M., Gustavo (2006), "Algunas reflexiones en torno a la problemática del acceso de las Pymes a los Servicios Financieros", Santiago: SBIF, p. 13. Disponible en http://www.sbif.cl/sbifweb/internet/archivos/DISCURSOS_4971.pdf Consultada el 12 de octubre de 2011). 
dades de financiamiento intermediado, cualquiera sea el modelo que ellas adopten, lo que ha llevado precisamente a los Estados en que se aplica tal mecanismo a asumir, por diversas vías y técnicas de subsidio, una activa participación en la generación de las condiciones regulatorias y de apoyo financiero necesarias para ello. Este soporte estatal sin embargo, que los arts. 32 y ss. de la LSGR le encomiendan explícitamente a los organismos y servicios públicos autorizados para ello, no se ha reflejado a nuestro entender en políticas y programas del todo eficientes e incluso consistentes unos con otros por parte del Estado chileno, principalmente a través de CORFO. Sobre este aspecto volveremos más adelante, al tratar sobre la intervención del Estado en el modelo chileno de SGR.

\section{b) Asesoramiento}

Según el art. 3, letra a) inc. $2^{\circ}$ de la LSGR, las SGRs estarán facultadas también para "prestar asesoramiento técnico, económico, legal y financiero a los beneficiarios", lo que refuerza por ende su carácter de herramienta de apoyo al emprendimiento Pyme. La concreta referencia a esta actividad, en forma expresa como se acaba de señalar, se justifica si consideramos que la ley configura este subtipo societario como uno de objeto exclusivo, en donde la autonomía de la voluntad de los accionistas se encuentra fuertemente restringida en punto a la determinación del objeto o giro social.

La ley chilena ha puesto especial atención entonces en la necesidad de complementar el apoyo financiero que se otorga a la Pyme, a través del afianzamiento de sus obligaciones con terceros, con el respaldo que tales empresas requieren en cuanto a su planificación y gestión de negocios. Uno de los factores que dificultan el dinamismo de la Pyme, resultante acaso de los factores que mencionábamos supra, consiste precisamente en sus deficientes estructuras jurídico-empresariales ${ }^{35}$ y en la falta de recursos técnico-profesionales suficientemente cualificados al interior de las empresas. Tal aspecto, manifestado en la improvisación con que muchas de ellas operan a la hora de planificar, administrar y ejecutar sus proyectos productivos, constituye a su vez un elemento que incentiva generalmente las desconfianzas del mercado crediticio de cara al financiamiento externo de tales emprendimientos, en una suerte de círculo vicioso que la ley procura romper finalmente mediante el asesoramiento adicional que pueden prestar las SGRs. Amén de garantizar la operación de crédito, en fin, la SGR le proporciona al empresario una guía especializada y eficaz para el

35 En Chile, según estudios de la SBIF, más del 70\% de la Pyme bancarizada está compuesta por empresarios personas naturales, de los cuales un $93 \%$ corresponden a microempresarios, $75 \%$ a medianos empresarios y un $51 \%$ a la empresa mediana. Arriagada (2006) 11. 
análisis, evaluación y ejecución de sus proyectos, lo que mejora sustancialmente la presentación de los mismos ante la banca y los oferentes de crédito en general.

Se trata, en fin, de una función inherente al mecanismo de financiamiento intermediado que proporciona la SGR, tanto en Chile con en el derecho comparado.

\section{c) Administración de fondos de reafianzamiento}

Por último, la misma disposición legal antes citada autoriza a la SGR para administrar los fondos de garantía a que se refiere el art. 33 de la misma ley, que faculta a su turno a los organismos y servicios públicos autorizados para aportar recursos financieros a uno o más fondos de inversión privados. La única finalidad de tal aporte -aclara además la normaconsiste en "afianzar las obligaciones que, por su parte, la Institución afiance y que constituyan el objeto del fondo (...)".

Los fondos, que pueden ser administrados como se dijo por la misma SGR, se rigen por lo dispuesto en el Título V de la LSGR, que regula el funcionamiento y fiscalización de las IGR por la Superintendencia de Bancos e Instituciones Financieras, y además por las normas contenidas en el Título VII de la Ley $\mathrm{N}^{\circ} 18.815$, sobre Fondos de Inversión, las que le serán aplicables por ende a la SGR en cuanto administradora de fondos autorizada por la ley.

A diferencia entonces de otros modelos, que optan por un sistema de reafianzamiento con base en la interacción de dos sociedades distintas (la SGR y la Sociedad Anónima de Reafianzamiento ${ }^{36}$ como entes jurídicos separados), la ley chilena ha preferido canalizar el aporte estatal a que se refiere el art. 32 por una vía distinta, recurriendo para ello a una figura jurídica preexistente y de probada eficiencia en el ordenamiento chileno: los fondos de inversión regulados en la Ley $\mathrm{N}^{\circ} 18.815$ y, concretamente, los fondos de inversión privados -FIP-.

No existen en el trámite legislativo mayores antecedentes sobre las razones y fundamentos que llevaron a optar por esta variante, que no se

36 Así por ejemplo ocurre en el sistema espańol, en donde conjuntamente con las sociedades de garantía recíproca operan las denominadas Sociedades de Reafianzamiento, reguladas en la Ley $1 / 1994$-de 11 de marzo- y en el RD $1644 / 1997$ y concebidas como entidades esencialmente participadas por el Estado, cuya constitución (a diferencia de lo que ocurre con la SGR en Chile) requiere de autorización administrativa previa. Algo similar se da también en el caso venezolano, estructurado precisamente con base en las SGRs -que pueden ser nacionales o regionales- y en los denominados "fondos nacionales de garantías recíprocas", que se constituyen también bajo la forma de sociedades anónimas con participación estatal (arts. 5 y ss. del Decreto con Rango y Fuerza de Ley N²51, Diario Oficial el 11 de agosto de 1999). 
contemplaba por cierto en el proyecto original ${ }^{37}$. Sin embargo, nos parece que el propósito de dicha estructura es doble y tiende, en cada caso, a generar las condiciones necesarias para que el diseńo escogido por el legislador pueda autosustentarse en su etapa de madurez a largo plazo, sin la intervención financiera del Estado en cuanto factor determinante. Revisemos este aspecto por separado:

a) En primer término, en efecto, por esta vía se logra mantener una radical separación entre la propiedad de los recursos estatales -por un lado- y su administración - por el otro-, asumiendo así el Estado un rol subsidiario en cuanto a la gestión de los mismos. La primera -la propiedad- queda radicada y se refleja en la adquisición de cuotas por parte de CORFO, que asume por ende la calidad de aportante del fondo respectivo. La segunda en cambio -la administración- queda reservada a la SGR en cuanto administradora del fondo ex art. 3.a) de la ley, sin que exista una injerencia directa del Estado aportante como ocurre, por ejemplo, con las sociedades de reafianzamiento del sistema espańol antes mencionadas (sin perjuicio de las atribuciones propias de la Asamblea de aportantes, claro está) ${ }^{38}$.

b) En segundo lugar, la administración que se le confiere a la SGR constituye sin duda un incentivo para aquellos inversionistas interesados en desarrollar una industria que, como ya se dijo, es aun insipiente en nuestro medio. Por esa vía, pues, los inversores pueden acceder a una rentabilidad adicional reflejada esta vez en las comisiones a que tiene derecho la SGR, como entidad administradora del fondo, las que se incrementarán además en la medida que dicha gestión de administración sea activa y eficiente $^{39}$.

37 La opción por los fondos de inversión surgió en el marco del primer informe de la Comisión especial de Pyme, a raíz de una indicación del ejecutivo para introducir al proyecto de ley original el art. 31 nuevo (Historia de la ley.., op. cit., p. 98).

El sistema adoptado por la LSGR es consistente además con lo que seńala el art. 25 inc. $6^{\circ}$ de la Ley $N^{\circ} 6.640$ (Ley Orgánica de CORFO), que contempla una vía indirecta de apoyo crediticio por parte de la referida entidad de fomento. Según la norma seńalada, en efecto, complementada ahora por lo dispuesto en el art. 33 de la Ley $\mathrm{N}^{\circ}$ 20.179, "La colocación de recursos crediticios de la Corporación será efectuada solamente a través de préstamos a bancos, instituciones financieras y empresas de leasing. Su objeto será financiar proyectos de inversión en los rubros que determine su Consejo".

39 Sobre la forma de calcular el monto de la comisión que puede cobrar actualmente la SGR al Fondo, véase el Programa $I G R-I I I$, apartado 4, letra h). Dicha comisión, con todo, es sustancialmente menor a la que pueden cobrar aun aquellas SGRs constituidas durante la vigencia del Programa IGR-I, actualmente aplicable para ellas, lo que genera una clara discriminación arbitraria en el tratamiento que reciben unas y otras. 


\subsection{3.) Órganos sociales}

En Chile la SGR puede constituirse como una sociedad anónima cerrada o abierta que se rige por las normas de la LSA, sin perjuicio de las reglas especiales contempladas en la ley $\mathrm{N}^{\circ} 20.179$ y que configuran, como se dijo supra, un estatuto particular para este subtipo societario. Por ende, y en lo que concierne a los órganos sociales, la SGR no difiere sustancialmente de una sociedad anónima cerrada o abierta. Sin embargo, y considerando la función de intermediación financiera que se le asigna a estas entidades, la ley establece algunos requisitos adicionales que resulta pertinente comentar en esta parte.

En efecto, según el art. 17 de la LSGR, para ejercer su actividad las sociedades de garantía recíproca deben inscribirse previamente en el Registro de Instituciones de Garantía Recíproca de la SBIF, para lo cual la sociedad ya constituida - de aquí que no sean anónimas especiales- debe presentar una carta solicitud a dicho organismo, en la que se indicará el nombre que llevará la sociedad y se describirán en forma sumaria las actividades que se propone realizar. Pues bien, según la Circular $N^{\circ} 1$ SBIF, sobre Sociedades de Garantía Recíproca, a dicha solicitud de inscripción "deberá adjuntarse un listado con los nombres completos y $N^{\circ}$ de Rol Único Tributario de los accionistas fundadores y el importe aportado por cada uno de ellos para conformar el capital social de la institución" 40 , lo que implica por ende que la conformación y funcionamiento válido de la Junta General de Accionistas, de cara al ejercicio del giro exclusivo de la sociedad, presupone necesariamente del cumplimiento previo del seńalado trámite administrativo; aun cuando se trate de una sociedad anónima cerrada.

Tratándose ahora del directorio como órgano de administración social, la Circular $\mathrm{N}^{\circ} 1$ precitada reitera la exigencia referida al señalar que en la misma carta-solicitud "se deberán individualizar las personas que forman el Directorio de la institución", agregando luego que dicho directorio "(...) debe estar compuesto por a lo menos tres directores en el caso de sociedades anónimas cerradas o cinco, si se tratare de sociedades anónimas abiertas, según lo dispone la ley $N^{\circ} 18.046$ ". Más aun, exige también la Circular que con la solicitud de inscripción se presente también "certificado de la Superintendencia de Quiebras, en el sentido de que los directores de la sociedad no están afectos al impedimento de haber sido declarados en quiebra o que, en caso que lo hayan sido, se encuentran legalmente rehabilitados", agregando también que, "De igual modo, se incluirán certificados relativos a las mismas personas y a las que conforman la planta gerencial, respecto de que no han sido 
condenadas o sometidas a proceso por crimenes o simples delitos de acción pública ${ }^{41}$. De esta forma entonces, la disposición reglamentaria supera con mucho el umbral que establece el art. 35 de la LSA, que fija precisamente los impedimentos generales para ser director de una sociedad anónima. En su numeral $3^{\circ}$, en efecto, la norma legal citada se refiere únicamente -en lo que aquí interesa- a los fallidos o los administradores o representantes legales de personas fallidas "condenadas por delitos de quiebra culpable o fraudulenta y demás establecidos en los artículos 203 y 204 de la Ley de Quiebras", sin extender dicha prohibición a quienes no hubiesen sido condenados por tales delitos, como lo hace la Circular referida.

La exigencia reglamentaria adicional entonces, al exceder el marco legal que fijan para estos efectos la LSGR y la LSA, respectivamente, constituye a nuestro juicio un ejercicio potestativo que supera el estándar de legalidad del actuar administrativo, con las consecuencias que de ello se derivan a la luz de los arts. 6 y 7 de la Constitución Política de 1980.

\subsection{4.) Capital}

Diversos son los aspectos que deben abordarse en este punto, cada uno distintivo de la SGR de cara a la regulación de las sociedades anónimas en general. A modo de observación general, sin embargo, debe destacarse que en estas sociedades el capital asume una función esencialmente garantista de cara a los terceros acreedores de los créditos otorgados a los beneficiarios, más que de explotación social según pasamos a revisar ${ }^{42}$.

\section{a) Capital mínimo}

A diferencia de las sociedades anónimas reguladas únicamente por la Ley $\mathrm{N}^{\circ} 18.046$, la Ley $\mathrm{N}^{\circ} 20.179$ establece para estas sociedades en particular la obligación de contar con un capital mínimo inicial equivalente a 10.000 Unidades de Fomento, el que deberá mantenerse como patrimonio también mínimo durante toda la vigencia de la sociedad (art. 3.c de la LSGR).

Nótese que la ley habla aquí, en un mismo literal incluso, de capital mínimo inicial - por una parte- y patrimonio mínimo -por la otra-, no obstante que ambos conceptos -capital y patrimonio- no pueden confundirse entre sí. "La confusión entre estos dos instrumentos de la vida social

Circular $\mathrm{N}^{\circ} 1 \mathrm{SBIF}$, apartado $2^{\circ}$

En el mismo sentido García Villaverde, Rafael (1980) "Las sociedades de garantía recíproca", en Revista de Derecho Mercantil, N 155 (enero- marzo 1980), pp. 71-95. 
-dice Vivante ${ }^{43}$-, uno formal y otro material, puede dar lugar a muchos equívocos peligrosos para la interpretación de la ley, si aquellos no se mantienen separados", lo que refleja precisamente la confusa situación que genera el texto del art. 3 letra c) de la LSGR, antes mencionado.

El patrimonio, en efecto, es un concepto esencialmente cambiante, compuesto por la cuenta de capital y también por las utilidades, pérdidas y reservas legales o estatutarias, mientras que el capital social es una cifra estática fijada en el estatuto, que cumple una función contable ${ }^{44}$ y también jurídica y cuya existencia es de derecho y no de hecho. Según el mismo autor, por lo mismo, "La diferencia entre el patrimonio, siempre mudable, y el capital, cifra constante, no está acompañada en el balance por ninguna variación del capital fijo, sino por la variación de los fondos accesorios, de las reservas, de los beneficios y de las pérdidas que, sumados al capital, equivalen al entero patrimonio de la sociedad. El capital constituye un asiento constante en la formación del balance social (...)”. Es este el sentido que debe dársele por lo demás al capital a que se refiere el art. $4 \mathrm{~N}^{\circ} 5$ de la LSA, en relación con los arts. 10 y 11 de la misma ley -todos aplicables a la SGR como ya se dijo-, de manera que para la LSA el concepto jurídico de capital coincide con la suma nominal del monto de las acciones en que este se divide y constituye, por lo mismo, un pasivo no exigible para la sociedad, que habrá de restituirse a los accionistas en los términos del art. 117 de la LSA. El patrimonio, reitero, es una cosa muy distinta, que solo coincidirá con el capital social al momento de constituirse la sociedad ${ }^{45}$.

Aclarado lo anterior, queda por definir entonces si el art. 3 letra c) de la LSGR, al utilizar los dos conceptos antes indicados, lo hace considerándolos en su correcta dimensión -y por ende como términos distintoso, por el contrario, los asimila conceptualmente como una misma cosa, pese a lo dicho supra. Tal definición no es en modo alguno indiferente, pues en el primer escenario tendría que aceptarse el caso de una SGR con

43 Vivante, César (1922-1926). Trattato di diritto commerciale, Tomo II, Le società commerciali, 5a edición. Milán: Francesco Vallardi, p. 192.

44 Sobre la preparación de los estados financieros de las sociedades anónimas abiertas en general y el tratamiento contable del capital y de las restantes cuentas de patrimonio, puede consultarse la Circular $\mathrm{N}^{\circ} 1.501$ del la Superintendencia de Valores y Seguros -SVS-, de 4 de octubre de 2000, modificada por la Circular SVS N 1.699, de 31 de diciembre de 2003. Dicha normativa, si bien no se aplica a las SGRs constituidas como S.A. cerradas, permite diferenciar también los conceptos de patrimonio y capital en su esfera financiero-contable.

45 Según BrunetTi, el capital social "corresponde al valor total de las acciones suscritas" o "la suma del capital-acciones". "Económicamente -agrega- corresponde al patrimonio neto inicial de empresa, porque, en el acto de constitución, es también el capital efectivo de la sociedad”. Brunetti, Antonio (1960). Tratado del Derecho de las Sociedades, Tomo II, Sociedad por Acciones, Traducción de Felipe Solá Cañizares, Buenos Aires: Uteha, p. 80. 
un capital inferior a las 10.000 U.F. -durante su vigencia, claro está-, en la medida que su patrimonio fuese igual o superior a dicha cifra; mientras que en la segunda de las hipótesis planteadas tal posibilidad no sería legalmente admisible.

Pues bien, a primera vista debiésemos concluir que el legislador, al utilizar en un mismo literal dos conceptos diversos, lo ha hecho porque conoce precisamente el significado y el alcance de cada uno (art. 21 del Código Civil), con las consecuencias que de ello se derivan. Por ende, la tentación de optar por la primera de las hipótesis planteadas pareciera ser, a primera vista al menos, la más razonable y la única posible. Sin embargo, el panorama así descrito se complica sustancialmente al relacionar la disposición legal antes citada con otras de la misma ley, que tratan sobre la misma materia.

En efecto, según el art. 17 letra b) de la LSGR, "Para ejercer el giro de Institución de garantía Reciproca, se deberá acreditar previamente ante la Superintendencia de bancos e Instituciones Financieras: b) Que tienen un patrimonio igual o superior a 10.000 unidades de fomento, acreditado en conformidad a las instrucciones que imparta la Superintendencia. Estas mismas circunstancias deberán ser acreditadas, además, anualmente ante la Superintendencia”. Según la norma citada entonces, la SGR constituida en conformidad a las reglas especiales del art. 3 solo puede entrar en funcionamiento y desarrollar su giro exclusivo previa autorización de la SBIF, debiendo cumplirse para ello con una serie de requisitos. Entre estos, como se dijo, la ley exige que se le acredite al ente fiscalizador que la sociedad, antes de iniciar sus operaciones, cuenta con un patrimonio igual o superior al monto indicado, sin hablar ya de capital inicial como hace en el art. 3 letra c), lo que pareciera indicar a fin de cuentas que el legislador ha utilizado aquí dichos términos en forma indistinta, asimilándolos materialmente en torno a una concepción unívoca -aunque errónea- de capital social.

Sin embargo, la aproximación precedente tampoco puede sustentarse de modo indubitado por cuanto, como hemos dicho antes, el capital social y el patrimonio social siempre van a coincidir entre sí al constituirse la sociedad y antes de que esta dé curso a sus operaciones. Por lo mismo, la utilización del término patrimonio que hace el art. 17 letra c) bien puede entenderse en este sentido restrictivo o de fase primaria, de patrimonio inicial igual al capital social, sin perjuicio de las diferencias sustanciales que presentan ambos conceptos y que el propio legislador ha destacado en otras oportunidades ${ }^{46}$. 
En síntesis, y considerando principalmente la finalidad que la ley le asigna a la SGR como entidad intermediadora de crédito y vehículo de apoyo financiero indirecto a la Pyme, entendemos que el capital mínimo inicial a que se refiere el art. 3 debe mantenerse como tal durante toda la vigencia de la sociedad; aun cuando la ley no lo seńale expresamente y pese a la notoria confusión conceptual que muestra en este sentido. Para sostenerlo así pueden mencionarse los siguientes fundamentos:

a) En primer término, debe considerarse que la LSGR se inscribe dentro de un ámbito normativo -el derecho de sociedades- en donde el libre juego de la libertad de los socios, que asumen el carácter de contratantes en la fase constitutiva de la sociedad, se ve restringida por el ordenamiento jurídico a partir de ese preciso momento originario y durante toda su vigencia como sujeto autónomo de derecho, en torno al cual confluyen y se entrelazan múltiples y diversos intereses que se manifiestan tanto en las relaciones internas que se generan entre los socios y la misma sociedad y/o sus administradores, cuanto respecto de los terceros que contratan o se vinculan jurídicamente con aquella. Tal fenómeno, por lo mismo, impone la necesidad de restringir la autonomía particular de las partes a la hora de definir sus obligaciones y derechos societarios recíprocos, mediante normas imperativas o de ius cogens cuya infracción genera la nulidad de lo actuado y las responsabilidades civiles y/o administrativas -e incluso penales en ciertos casos- de quienes las han vulnerado.

A la luz de la teoría de la ficción que recoge el derecho chileno, además, la personalidad jurídica que surge del contrato de sociedad -y que la diferencia por lo mismo de los socios individualmente considerados- constituye un atributo que deriva en último término del Estado, que la crea y reconoce precisamente como resultado del cumplimiento de las formas y requisitos que el mismo ordenamiento jurídico, en base a razones de orden público y de seguridad jurídica, ha definido para ese preciso efecto. Con todo, se trata aquí "de una regulación de ius cogens o derecho necesario, pero solo de minimos" ${ }^{7}$, de manera que los socios o accionistas bien pueden superar el piso o umbral normativo, pero nunca rebajarlo.

un plazo para enterar el saldo. Sin embargo, mientras el banco no alcance el capital mínimo señalado en el artículo 50, deberá mantener un patrimonio efectivo no inferior al $12 \%$ de sus activos ponderados por riesgo, proporción que se reducirá al 10\% cuando tenga un patrimonio efectivo de 600.000 unidades de fomento...".

47 Así lo seńala la sentencia de la Audiencia Provincial de Madrid, de 24 de septiembre de 2002, Aranzadi Westlaw, JUR 2003122969. Un completo análisis de esta sentencia se encuentra en Fernández del Pozo, Luis (2006) "La arbitrabilidad de un derecho estatutario de separación por 'justa causa' en una Sociedad Anónima. En torno a la STC 9/2005, de 17 de enero de 2005”, en Revista de Derecho de Sociedades, № 26, pp. 282 y ss. 
De lo dicho se desprende entonces que la exigencia del art. 3.c) de la Ley $\mathrm{N}^{\circ} 20.179$ constituye un elemento distintivo de la SGR, establecido con base en su objeto social específico y que la sitúa por lo mismo dentro del reducido elenco de sociedades anónimas que requieren en Chile de un capital mínimo para constituirse y/o para funcionar (v. gr. los bancos, las administradoras de fondos autorizados por ley, las bolsas de valores, compañías de seguros, etc.). Tal exigencia, excepcional como se dijo en el derecho chileno de sociedades de capital, se explica precisamente por la especial función que la ley le asigna a la sociedad de cara a los intereses suprasocietarios involucrados en su gestión, asumiendo por ende una clara función de garantía que matiza en alguna medida -insuficiente a nuestro entender- la responsabilidad limitada de los accionistas por las obligaciones sociales.

En conclusión, el capital mínimo de la SGR constituye un elemento configurador de este subtipo societario, establecido por la ley con miras a la tutela de intereses que trascienden al puro interés individual de los accionistas y que, por lo mismo, resulta indisponible en todo lo que afecte al seńalado minimum legal. En este entendido cobra además pleno sentido el art. 3.c) de la LSGR, que amén de exigir un capital social mínimo ab initio, requiere también un patrimonio mínimo ex post para impedir precisamente que el primero, por obra y determinación de los accionistas, se transforme en la variable puramente nominal de un patrimonio cargado de pérdidas, de ninguna significación financiera real por ende. Como apunta Puga ${ }^{48}$, en fin, "sociedades con grandes pérdidas pueden alienar su capital social en breve tiempo y sociedades con grandes utilidades acumuladas pueden figurar con capitales estatutarios menores".

b) Por otra parte, el art. 7 de la LSGR establece que toda institución de garantía recíproca deberá constituir un fondo de reserva patrimonial con cargo a los resultados de la operación social, el que estará destinado a absorber las pérdidas futuras. Dicho fondo será “de un valor equivalente, al menos, al $20 \%$ del capital" (art. 7 inc. $1^{\circ}$ ) y "se incrementará con los montos que se generen por la parte proporcional de las utilidades que correspondan a los accionistas (...), debiendo destinarse a lo menos un 25\% de ese monto para aumentar dicho fondo" (art. 7 inc. $3^{\circ}$ ). Mientras el fondo no acumule recursos por el $20 \%$ mínimo del capital pagado, no podrán repartirse dividendos (art. 7 inc. $2^{\circ}$ ).

Pues bien, parece claro que al referirse la ley al capital y luego al capital pagado, tomándolo como base de cálculo del monto mínimo del fondo de reserva y como umbral habilitante de la distribución de 
utilidades - respectivamente-, lo hace en el entendido de que dicho capital no puede ser nunca inferior al establecido en el art. 3.c); ni en el estadio fundacional de la sociedad ni durante su vigencia. De lo contrario, en fin, bastaría con que la junta extraordinaria de accionistas acordara rebajar el capital social -manteniendo el patrimonio en el rango legal mínimo- para que el monto mínimo del fondo de reserva patrimonial se viera afectado consecuencialmente, por efecto precisamente de la rebaja convencional de su base de cálculo. Todavía más, por esta vía los accionistas podrían burlar incluso las pautas que establece la ley para la distribución de utilidades, rebajando simplemente el capital pagado de la sociedad y con ello el monto mínimo del fondo de reserva, en perjuicio de los acreedores garantizados y en fraude de la ley.

c) Por último, el art. 23.a) de la LSGR, al tratar sobre las medidas para enfrentar la insolvencia de la SGR, distingue sin duda entre el capital mínimo y el patrimonio de la sociedad, presumiendo la insolvencia de la misma cuando su patrimonio, después de descontadas las pérdidas acumuladas del ejercicio en que se generen, "sea inferior al capital mínimo señalado en el artículo 3".

En síntesis, y pese a las notorias deficiencias que evidencia la ley en esta parte, a nuestro entender el capital mínimo a que se refieren los arts. 3.c), 7 y 17 de la LSGR no puede ser rebajado por la junta extraordinaria de accionistas. Un acuerdo en tal sentido, por lo mismo, sería nulo e impugnable como tal por un accionista disidente o por cualquier tercero interesado, tal como lo señalan expresamente aquellas normativas que sirvieron de modelo a la chilena ${ }^{49}$.

Distinta es la situación si la reducción del capital estatutario no infringe el mínimo legal ya mencionado ni afecta el piso de solvencia patrimonial que establece la ley en el art. 3.c, pues en tales casos no existe razón alguna para limitar la autonomía de la voluntad de los accionistas. Por lo mismo, y considerando nuevamente la función de intermediación financiera que cumple la SGR de cara al acceso eficiente de la Pyme al crédito, echamos en menos en esta parte una

49 Así por ejemplo, el art. art. 7.2 de la ley española señala en este sentido que "La reducción del capital social por debajo de la cifra minima fijada en los estatutos o el aumento del mismo por encima del triple de dicha cantidad exigirán el acuerdo de la Junta general, adoptado según los requisitos establecidos para la modificación de estatutos". El mismo art. 7, en su tercer numeral, aclara que "En cualquier caso, las reducciones del capital social previstas en los dos apartados anteriores no podrán ser válidamente acordadas sin respeto de los requisitos minimos de solvencia". El art 49.3 de la misma ley, por su parte, seńala que "Será nulo también el acuerdo de reducir la cifra del capital social a una cantidad inferior a la establecida en el artículo 8", que a su vez establece que "El capital social minimo de las sociedades de garantía recíproca no podrá ser inferior a 300.000.000 de pesetas” (art. 8.1). 
mayor protección y mecanismos de resguardo mínimo para aquellos acreedores de los accionistas o de terceros que han sido garantizados por la SGR y que, precisamente, tuvieron en cuenta la situación de solvencia del garante al momento de aceptar y recibir su garantía. Es este el objetivo que persigue por ejemplo el art. 49.1 de la ley española, al conceder un derecho de oposición a los acreedores de los socios partícipes a cuyo favor la SGR ha dado una garantía. Como contrapartida de la limitación de responsabilidad de los socios que la ley establece respecto de las obligaciones sociales, a dichos acreedores se les reconoce incluso la facultad de impetrar la suspensión temporal de la ejecución de un acuerdo de reducción de capital de la SGR, en tanto no se les garantice adecuadamente el pago de sus créditos, lo que constituye a nuestro entender un resguardo lógico y necesario para el adecuado funcionamiento y la confiabilidad de este particular sistema de garantías ${ }^{50}$.

\section{b) Capital suscrito y capital pagado}

Un segundo aspecto relacionado con el capital social consiste en determinar si a este subtipo societario se le aplica la norma del art. 11 de la LSA, que permite constituir válidamente una sociedad anónima con la sola estipulación y suscripción de su capital, postergando el pago de las acciones respectivas hasta por un plazo máximo de tres años.

A diferencia de lo que ocurre en otros casos, en que la ley resuelve expresamente este punto ${ }^{51}$, la LSGR nada dice en este sentido por lo que, en principio, debiese aplicarse la norma recién mencionada sin mayores restricciones. Por lo demás, el art. $1^{\circ}$ de la mencionada ley hace aplicables las normas de la Ley $\mathrm{N}^{\circ} 18.046$, sin seńalar una regla especial diversa en el art. 3, a lo que debe sumarse la circunstancia de que el art. 6 de la señalada LSGR confiere un amplio marco de acción a la autonomía de la voluntad de los accionistas a la hora de definir en qué instrumentos o

50 Para hacer efectivo el ejercicio de este derecho, la ley española le asegura a los acreedores garantizados una amplia información respecto de cualquier acuerdo de reducción de capital, imponiéndole a la SGR el deber de publicar dicho acuerdo por tres veces en el Boletín Oficial del Registro Mercantil y en tres periódicos de los de mayor circulación en la provincia donde la sociedad tenga su domicilio, además de notificar directamente a las entidades acreedoras de los socios partícipes a favor de las cuales haya prestado garantía la sociedad. Practicada la publicación del último anuncio -agrega la norma citada-, la reducción de capital no podrá llevarse a cabo durante un mes, plazo que se le otorga precisamente a los acreedores para ejercer su derecho de oposición.

51 Así por ejemplo, el art. 7 del D.F.L. $N^{\circ} 251$, sobre Compañías de Seguros, seńala expresamente que la autorización de existencia de las compañías de seguro presupone que el capital mínimo que establece la misma disposición se encuentre íntegramente suscrito y pagado al momento de la constitución. Lo mismo ocurre con las sociedades administradoras de fondos de terceros en general (v. gr. art. 3.c de la Ley $\mathrm{N}^{\circ} 18.815$ ) y con los bancos (art. 50 de la Ley General de Bancos), entre otros. 
activos se invertirá dicho capital, lo que parece reforzar la conclusión anterior.

Sin embargo, debemos reiterar en esta parte lo seńalado supra en cuanto a la especial función que se le asigna a la SGR en el sistema financiero chileno y a la finalidad que debe cumplir, por ende, su capital mínimo. En tal sentido, pues, podemos decir con De la Cuesta y González ${ }^{52}$ que la función de garantía del capital la cumple no el capital suscrito de la SGR sino su capital mínimo enteramente pagado o desembolsado ${ }^{53}$, de manera que aun cuando la ley chilena no lo señale expresamente -como hubiésemos esperado por cierto-, la exigencia de capital mínimo no se justifica si no va acompańada de la obligación de desembolso íntegro del mismo, al momento de la constitución de la sociedad o a lo menos al requerirse la autorización de funcionamiento a que se refiere el art. 17 de la LSGR $^{54}$, según lo señala -aunque de modo impreciso- la Circular $\mathrm{N}^{\circ} 1$ de la SBIF, ya mencionada, capítulo I, N³.

Con todo, nada impide que la SGR cuente con un capital suscrito y no pagado superior al mínimo legal, el que se regirá -ahora sí- por las normas ya citadas de la LSA.

\section{c) Forma de enterar el capital}

Otro aspecto no resuelto por la LSGR consiste en determinar si el pago de las acciones que conforman el capital social de la SGR debe hacerse solo en dinero o si, por aplicación del art. 15 de la LSA, puede realizarse también "con otros bienes" si los estatutos así lo autorizan.

52 De la Cuesta Rute, José María y González Vásquez, José Carlos (2000) "Modificación de estatutos, aumento y reducción de capital social en la sociedad de garantía recíproca”, en Revista de Derecho Bancario y Bursátil, ańo 19, N 80, p. 130.

53 Así lo seńala también la ley espańola sobre SGR, cuyo art. 8 parte con el encabezado "Importe exigido para la cifra mínima del capital social desembolsado".

54 La misma norma, en su literal c), seńala que será la SBIF la encargada de fijar mediante instrucciones las pautas de acreditación del patrimonio mínimo legal. En este sentido, la Circular $\mathrm{N}^{\circ} 1 \mathrm{SBIF}$, sobre " Normas generales para firmas evaluadoras de instituciones de garantía recíproca”, cuyo Capítulo II trata precisamente sobre el contenido del informe de fiscalización a que se refiere a su turno el art. 18 de la LSGR, seńala en su letra d) que entre los aspectos a informar se cuenta precisamente el deber de "constatar que las politicas y procedimientos vigentes en materia de solvencia permiten una evaluación continua de la base patrimonial requerida para enfrentar las pérdidas inesperadas asociadas a sus operaciones, considerando para ello tanto las exposiciones dentro como fuera de balance y los efectos mitigadores de las contragarantias y reafianzamientos disponibles". Tratándose del primer informe de evaluación, además, la circular referida destaca especialmente la necesidad de verificar que la estructura del capital social mínimo de toda SGR que opte a la clasificación en categoría "A", según el artículo 18 de la Ley y el Título II de la Circular para Sociedades de Garantía Recíproca, "debe centrarse en el cumplimiento de los requisitos de capital mínimo y los activos en que se encuentra invertido", lo que presupone también su entero desembolso. 
Nuevamente, y a diferencia de lo que ocurre con otras sociedades anónimas de capital mínimo ${ }^{55}$, la LSGR nada dice en este punto. Por lo mismo, y por disponerlo así el art. $1^{\circ}$ inc, $1^{\circ}$ de la referida ley, pareciera que la alternativa que concede el art. 15 de la LSA bien podría tener lugar también este caso.

Sin embargo, nos parece que tampoco resulta posible extrapolar el mecanismo común o general de entero de los aportes de la LSA a la particular figura de la SGR:

a) En primer término, el art. 6 inc. $1^{\circ}$ de la LSGR señala que "Los recursos de la Institución de Garantía Reciproca, deberán ser invertidos en los instrumentos y otros bienes expresamente autorizados por su respectivo estatuto (...)", lo que supone por ende la existencia de recursos líquidos que puedan ser invertidos precisamente.

b) El art. 15 de la LSA, si bien permite el pago de las acciones con otros bienes, exige que en tales casos los aportes sean estimados por peritos "salvo acuerdo unánime de las acciones emitidas". En consecuencia, y tratándose concretamente de las sociedades anónimas de garantía recíproca, la avaluación por unanimidad de los bienes aportados a la sociedad podría derivar en una eventual manipulación por parte de los accionistas de los mínimos legales de capital y de solvencia patrimonial establecidos en el art. 3 de la LSGR, ya citado, con el consiguiente riesgo para los acreedores que han recibido certificados de fianza emitidos por la sociedad.

Por lo dicho entonces, nos parece que el silencio de la ley en esta parte no puede ser suplido por la aplicación del mecanismo legal contemplado en el art. 15 de la LSA, pues sus consecuencias resultan del todo incompatibles con la exigencia de capital y patrimonio mínimos.

\section{d) Infracapitalización e insolvencia de la SGR}

Un aspecto que llama la atención es que la LSGR chilena, junto con exigir un capital social mínimo en la constitución de la sociedad y durante toda su vigencia, no ha contemplado al mismo tiempo, como concreta causal de disolución de la misma, la disminución de dichos mínimos durante un periodo determinado. Lejos de ello, en su art. 27 la ley se limita a invocar simplemente las causales de disolución contempladas a su turno en la LSA, consignando luego algunas excepciones que, en lo que aquí concierne, no alteran lo recién señalado. Todavía más, de la lectura de los arts. 23 y ss. de la misma ley se desprende que el legislador chileno no ha querido consagrar la infracapitalización sobrevenida como una causal de

Así por ejemplo, el art. 49.1 de la Ley General de Bancos seńala expresamente que "Los aportes de los accionistas sólo podrán consistir en dinero efectivo, esto es, en moneda legal de Chile (...)". 
disolución de la sociedad, lo que presupone un tratamiento normativo también particular de cara al fenómeno de la insolvencia de la SGR.

Desde luego, y considerando que la SGR no es una sociedad anónima especial como ya se dijo, la ley no ha podido contemplar aquí, como medida conservativa de última ratio frente al estado de insolvencia de la misma, la revocación de la autorización de existencia que sí se contempla en cambio cuando se trata de bancos y compañías de seguro ${ }^{56}$, por poner algunos ejemplos. Sin embargo, la LSGR no ha contemplado tampoco una causal de disolución equivalente a la señalada revocación, optando en cambio por replicar los mecanismos de prevención, mitigación y control de insolvencia establecidos para los bancos en el Título XIV de la Ley General de Bancos -LGB-, Párrafos $1^{\circ}$ y $2^{\circ}$, aunque sin llegar, como ya se dijo, a la disolución como sanción. Así, la ley le impone a la SGR y a sus administradores las mismas obligaciones de capitalización y de información que establecen los arts. 118 y 119 de la LGB, respectivamente, a lo que se suma la obligación que tiene el directorio de ambas sociedades -SGR y bancos- en orden a presentar proposiciones de convenio judicial preventivo a los acreedores, "en el plazo de 10 días contado desde que se haya detectado la falta de solvencia" (art. 25 de la LSGR y art. 122 de la LGB), pero en ninguna parte se refiere a la disolución de la sociedad como sí lo hace, v. gr. la ley espańola ya mencionada ${ }^{57}$.

La diferencia sustancial entonces, entre la normativa aplicable a los bancos y a la SGR en insolvencia, radica en que si bien en ambos casos se ha optado por evitar la disolución de pleno derecho de la sociedad, en el caso de los bancos la decisión en tal sentido se la entrega la ley al Superintendente de la SBIF vía revocación de la autorización de existencia (art. 130 LGB), mientras que en la SGR la disolución por insolvencia queda supeditada a una declaración previa de quiebra por sentencia firme y a la declaración judicial también ejecutoriada dada en los términos del art. 105 de la LSA. Nunca podrá quedar sujeta sin embargo a la autorización adicional de los acreedores, como podría desprenderse de lo señalado por el art. 28 inc. $1^{\circ}$ de la LSGR, pues entendemos que dicha norma $-y$ tal autorización- solo resulta aplicable a los casos en que la disolución se origina en un acto volitivo de la sociedad (art. $103 \mathrm{~N}^{\circ} 3$ y $\mathrm{N}^{\circ} 6$ de la LSA)

56 Así lo seńala el art. 73 del D.F.L. $\mathrm{N}^{\circ} 251$, tratándose de las compańías de seguro, y el art. 130 de la LGB en el caso de los bancos, ambos en relación con el art. $103 \mathrm{~N}^{\circ} 4$ de la LSA.

57 El art. 59.1.d) y e) de la ley española contempla, como causal de disolución de la SGR, la reducción del capital social desembolsado por debajo de la cifra mínima exigida en la ley y la existencia de pérdidas que dejen reducido el patrimonio social neto a una cantidad inferior a las dos terceras partes del capital social, a menos que los socios aumente dicho capital en la medida necesaria o se reduzcan las pérdidas en la proporción requerida. 
o de sus accionistas individualmente considerados (art. $103 \mathrm{~N}^{\circ} 2$ ), como pasamos a revisar.

\subsection{5.) Derechos y obligaciones de los accionistas}

En lo que concierne a los derechos y obligaciones de los accionistas de una SGR, la ley $\mathrm{N}^{\circ} 20.179$ establece una serie de particularidades de interés que serán abordadas por separado.

\section{a. Derecho a voz y voto y derecho a participar en Junta del accionis- ta moroso}

Una de las notas más distintivas y vistosas que presenta la SGR en Chile, de cara al estatuto jurídico que regula a las sociedades anónimas en general, consiste precisamente en la restricción amplia que impone el art. 10 de la LSGR en cuanto al ejercicio del derecho del accionista a participar en Junta y a votar en ella, entre otros.

Según la norma señalada, en efecto, "Los demás derechos sociales de los accionistas o socios beneficiarios [el art. 9 se refirió antes al derecho a dividendos] se suspenderán de pleno derecho en caso de mora o simple retardo en el cumplimiento de obligaciones que tuvieren con la entidad o de las afianzadas por esta", lo que implica - en lo que aquí concierne- que en la SGR el ejercicio del derecho a voz y voto se encuentra sujeto a condicionamientos y restricciones que superan con mucho el estándar contemplado para el mismo derecho en la LSA, según pasamos a revisar.

a.1) Regulación del derecho a voz y voto en la LSA:

a) En primer término, el art. 62 de la LSA se ocupa de definir el marco subjetivo y material en el que debe insertarse precisamente el ejercicio legítimo del derecho de voz y voto, distinguiendo para ello entre sociedades anónimas abiertas y especiales - por una parte- y sociedades anónimas cerradas, por la otra.

En la primeras -abiertas y especiales-, la única restricción al seńalado derecho consiste en que las acciones respectivas deben encontrarse inscritas en el Registro de Accionistas con a lo menos cinco días de anticipación a la fecha en que haya de celebrarse la Junta respectiva. En las cerradas en cambio $-y$ concretamente tras la modificación introducida al art. 62 de la LSA por la Ley $\mathrm{N}^{\circ} 20.382$ (D.O. de 20 de octubre de 2009)-, la ley prescinde incluso del mínimo temporal recién apuntado, exigiendo únicamente que las acciones respectivas se encuentren inscritas al momento en que deba iniciarse la junta. 
b) Lo señalado supra, con todo, es sin perjuicio de la existencia de acciones sin derecho a voto o con voto limitado, sea que tal condición se origine en un expreso mandato legal (v. gr. art. 27 inc. $3^{\circ}$ LSA) o en una disposición estatutaria concreta (v. gr. art. 21 LSA); pero aun en esos casos -aclara la misma norma en su inc. $2^{\circ}$ - las acciones señaladas conservarán el derecho a voz.

c) Todavía más, ni siquiera el accionista moroso puede ser privado del derecho de voto en junta, pues la LSA simplemente no lo priva de tal derecho. Por el contrario, el art 16 inc. final de la ley señala precisamente que salvo disposición estatutaria expresa, "Las acciones cuyo valor no se encuentre totalmente pagado gozarán de iguales derechos que las integramente pagadas, salvo en lo relativo a la participación que les corresponda en los beneficios sociales y en las devoluciones de capital (...)", sin distinguir si el plazo para el pago de las acciones suscritas se encuentra vencido o no.

\section{a.2) Regulación del derecho a voz y voto en la LSGR:}

Tratándose del derecho a voz y voto en junta de accionistas, el panorama normativo descrito supra es radicalmente distinto al que se aplica concretamente a la sociedad anónima de garantía recíproca.

En la SGR, pues, el ejercicio del señalado derecho de voz y voto en junta depende no solo del cumplimiento íntegro y oportuno de las obligaciones que contrae el accionista en su calidad de tal (principalmente el pago de las acciones suscritas), sino que también del pago de las obligaciones que este último haya contraído para con terceros, afianzadas por la sociedad. De esta forma entonces, la LSGR excede con mucho el ámbito restrictivo que contempla la LSA en punto al ejercicio del derecho mencionado, superando incluso el régimen contemplado en tal sentido por las legislaciones extranjeras que le sirvieron de modelo.

Sin embargo, nos parece que el mecanismo contemplado en el art. 10 de la LSGR resulta innecesariamente gravoso, al punto de perturbar incluso el regular funcionamiento de la sociedad y de sus órganos. Tan amplia es la restricción que establece aquí la ley, en efecto, que a partir de ella $-\mathrm{y}$ extremando las cosas- bien podría darse el caso de que los accionistas no pudiesen reunirse normalmente en junta, ordinaria o extraordinaria, por falta del quórum mínimo que el art. 61 de la LSA establece para constituirla (a lo menos mayoría absoluta de las acciones emitidas con derecho a voto), transformando así el mecanismo de la segunda citación en la regla general y no en la excepción. Por ello precisamente, el art. 38 de la ley espańola, bajo el rótulo "restricciones al ejercicio al derecho a voto", ha optado por limitar el ejercicio del derecho a voto -nunca el de voz- solo en aquellos casos en que el socio respectivo se encuentre inmerso en un conflicto de intereses al momento de emitir su voto, lo que evita -o atenúa al menos- los eventuales trastornos que puede sufrir el funcionamiento de la sociedad y caute- 
la de mejor forma la representatividad real de la voluntad de su accionariado ${ }^{58}$, con las importantes consecuencias que de ello se derivan.

\section{b) Derecho a ser afianzado por la sociedad y proporcionalidad entre el monto garantizado y el capital aportado. Límites generales y específicos de garantía}

Como se señaló al tratar sobre el objeto de la SGR como sociedad anónima, una de sus características distintivas consiste precisamente en la vocación mutualista que esta puede asumir de cara a sus accionistas y a los beneficios directos que estos reciben -o pueden recibir- de la sociedad, más allá de la participación en el reparto de sus utilidades.

Es ese mismo carácter o vocación, sin embargo, lo que lleva al legislador a exigir por contrapartida que los estatutos sociales definan a priori y de manera estable el monto máximo de las obligaciones de cada accionista que la sociedad puede afianzar, tomando como base de cálculo para ello el capital suscrito y pagado que cada uno haya aportado. Así lo señala el art. 5.3 de la LSGR -que recoge básicamente el texto del art. 18, letra p), de la ley espańola ya mencionada-, cuya finalidad apunta a asegurar un trato igualitario y no discriminatorio hacia los distintos accionistas/ potenciales beneficiarios de la sociedad por la vía de definir, en forma objetiva y con rango orgánico-estatutario, el ámbito material de ejercicio de tal derecho. El monto de las garantías a otorgar por la sociedad a sus accionistas individualmente considerados, en fin, dependerá de la participación que tenga cada cual en el capital social, lo que constituye un parámetro objetivo que define, concretamente, el limite subjetivo especifico de garantías que el accionista puede recibir.

Tratándose sin embargo del modelo chileno de SGR, que se aparta como se dijo de la finalidad puramente mutualista al permitir el afianzamiento de obligaciones contraídas por terceros que no sean accionistas, la ley ha tenido que añadir una segunda limitante estatutaria en este sentido, que podríamos denominar como limite objetivo general de garantias y que apunta a fijar, adicionalmente, "los porcentajes máximos de las garantias que la entidad puede otorgar en relación con su patrimonio, con el valor de los fondos de garantía que administre o con las contragarantias que se le haya rendido" (art. 5.2 de la LSGR).

Según el art. 38.2 de la señalada ley, "no será lícito el ejercicio del derecho de voto para adoptar una decisión que venga a liberar de una obligación a quien lo ejercita o para decidir sobre la posibilidad de que la sociedad haga valer determinados derechos contra él". Tal sería por ejemplo el caso en que la junta tuviese que decidir sobre la posible condonación de los dividendos pasivos del accionista o, por contrapartida, debiese resolver sobre la exclusión del socio moroso u optar por el cumplimiento compulsivo de sus obligaciones pendientes. 
En resumen, la ley chilena contempla aquí un sistema compuesto de limitantes para el otorgamiento de garantías por parte de la SGR, que complementado por la prohibición de gravar y enajenar acciones del art. 8 de la LSGR, surge precisamente de la dualidad que la misma ley permite de cara a los sujetos que pueden ser beneficiarios de aquella. Ambas vertientes delimitadoras por lo mismo, específicas y generales como ya se dijo, deben operar en forma armónica entre sí, sin perjuicio de la posibilidad $-y$ conveniencia- de acotar también en el estatuto los efectos de una eventual modificación de las señaladas proporciones por parte de la junta de accionistas ${ }^{59}$.

\subsection{6) Disolución de la SGR por unipersonalidad sobrevenida}

Hemos dicho ya que la disolución de la SGR se rige por las mismas causales contempladas en la LSA (art. 27 de la LSGR), sin hacer distingo ni precisión alguna, lo que nos lleva a determinar por ende el concreto alcance que debe dársele a la exigencia contemplada en el art. 28 inc. $1^{\circ}$ de la LSGR, de cara a la causal de disolución del art. $103 \mathrm{~N}^{\circ} 2$ de la LSA.

La parquedad del legislador en esta parte, matizada apenas por una remisión normativa genérica a las causales de disolución de la LSA, da pie para diversas alternativas y soluciones posibles, lo que genera por lo mismo un escenario interpretativo especialmente complejo.

En efecto, según el art. 28 citado, "La disolución, división y fusión de una Institución de Garantía Reciproca requerirá contar con la autorización previa y por escrito de los dos tercios de los acreedores del total de las deudas garantizadas por la misma en el ejercicio de su giro", de donde surge la necesidad de determinar (a) si la mencionada autorización previa debe considerarse como una formalidad habilitante que limita la libre cesibilidad de las acciones emitidas por la SGR en los casos de disolución por la causal del art. $103 \mathrm{~N}^{\circ} 2$ de la LSA, y (b) si dicha autorización es excluyente de

59 El carácter estatutario de esta mención resulta de la mayor relevancia en cuanto garantía de transparencia, estabilidad e igualdad de trato para los accionistas, pues si bien la junta de accionistas podría modificarla en cualquier momento, no podría incumplirla mediante acuerdos circunstanciales destinados a beneficiar a un(os) accionista(s) en perjuicio de otro(s) o de la propia sociedad, al concentrar $-y$ por ende incrementar- el riesgo de su operación. Con todo, nos parece conveniente que en este caso los estatutos contemplen también, ex art. $69 \mathrm{~N}^{\circ} 7$ de la LSA, una especial causal de retiro frente al acuerdo de la junta de accionistas que altere sustancialmente los márgenes estatutarios garantizables. Por esta vía, pues, se protege al minoritario disidente que, de lo contrario, podría verse obligado a renunciar a sus legítimas expectativas de negocio ante un aumento del margen de obligaciones garantizables a los accionistas - con la consiguiente reducción de los montos susceptibles de garantizar a terceros-, o a ser garantizado de manera suficiente y efectiva por la sociedad si dichos márgenes disminuyen ostensiblemente, por poner un ejemplo. 
o complementaria con aquella a que se refiere el art. 107 de la misma ley, en el caso de las sociedades fiscalizadas por la SVS.

\section{a) Una aclaración previa: la unipersonalidad sobrevenida como cau- sal de disolución de la sociedad anónima en la legislación vigente}

Para responder de manera adecuada a las interrogantes recién planteadas debemos advertir previamente que, en la actualidad, la reductio ad unum no involucra el fin automático de la sociedad anónima en Chile ${ }^{60}$.

En primer término, en efecto, según el art. 107 recién citado "Una sociedad anónima abierta o especial no inscribirá, sin el visto bueno de la Superintendencia [de Valores y Seguros], la transferencia o transmisión de acciones que pueda determinar la disolución de la compañia, por el hecho de pasar todas las acciones de la sociedad al dominio de una sola persona". Dicha autorización solo se otorgará -agrega la norma en su inciso $2^{\circ}-$ "cuando se hayan tomado las medidas conducentes a resguardar los derechos de los terceros que hubieren contratado con la sociedad".

Por otra parte, el legislador chileno dio recientemente un tímido aunque significativo paso adelante en este sentido, al condicionar la disolución a que se refería el texto original del art. $103 \mathrm{~N}^{\circ} 2$ de la LSA al hecho de que la unipersonalidad sobrevenida se mantenga "por un periodo ininterrumpido que exceda de 10 dias" 61. Lo anterior implica por ende que la sociedad puede subsistir en tanto y en cuanto la pluralidad accionaria se restituya en el plazo legal indicado, lo que coincide además con el mecanismo contemplado en el art. 71 bis de la LSA, que reconoce expresamente la posibilidad de que el controlador del $95 \%$ de una sociedad anónima abierta adquiera válidamente el 100\% de las acciones emitidas, sin que por ello se disuelva la sociedad antes de completarse el plazo mencionado.

Aclarado lo anterior, trataremos de dar respuesta entonces a las interrogantes planteadas supra.

60 A la unipersonalidad y su reconocimiento en el derecho chileno de sociedades nos hemos referido en otra oportunidad, a lo que nos remitimos ("Unipersonalidad y sociedad con un solo socio; alcances de su reconocimiento en la estructura dogmática del derecho chileno", en Revista Ius et Praxis, N¹7-2, junio de 2011, pp. 189 a 230).

El art. $103 \mathrm{~N}^{\circ} 2$ de la LSA fue modificado en este sentido por el art. 52, $\mathrm{N}^{\circ} 51 . \mathrm{b}$ ) de la Ley $\mathrm{N}^{\circ} 20.382$ (D.O. de 20 de octubre de 2009). La misma ley introdujo el art. 71 bis nuevo, que permite incorporar al estatuto social la posibilidad de compra forzada de las acciones de los accionistas minoritarios, cuando el controlador llega a adquirir el $95 \%$ o más del capital social. 


\section{b) El art. 28 de la LSGR y su aplicación a la causal de disolución del art. $103 \mathrm{~N}^{\circ} 2$ de la LSA}

Tal como señalamos al inicio de este apartado, la imprecisión del legislador al regular la disolución de la SGR mediante una simple remisión normativa a la LSA, estableciendo al mismo tiempo la exigencia también amplia del art. 28 de la LSGR en cuanto presupuesto para la disolución válida de la misma, genera no pocas dificultades a la hora de explicar el señalado mecanismo cuando la disolución viene dada por la reunión de todas las acciones en una sola mano. Se trata, por lo demás, de un aspecto de la mayor relevancia jurídica y práctica si consideramos que en estos casos no se requiere de la liquidación ulterior de la sociedad (art. 110 inc. $3^{\circ}$ de la LSA), de manera que la disolución coincide aquí -por excepción a la regla del art. 109 de la LSA- con la extinción simultánea de la personalidad jurídica ${ }^{62}$.

Pues bien, de la ambigüedad del escenario planteado resultan -por lo mismo- distintas alternativas de análisis y respuestas también variadas, cuyas consecuencias nos conducen a la vez por derroteros muy disímiles y hasta contradictorios entre sí, según pasamos a revisar.

A) Una primera posibilidad es considerar que la ley establece aquí una limitante especialísima para la enajenación válida de acciones de la SGR, no contemplada por cierto en la LSA, cuando producto de aquella se configura la causal de disolución ya dicha. Se trataría en consecuencia de un requisito adicional de validez del contrato de cesión de acciones propiamente tal, que obligaría al accionista cedente a obtener previamente la autorización de los acreedores en la proporción ya señalada.

No nos parece que sea esta una solución posible. Como se dijo supra, en la actualidad la reductio ad unum no constituye una causal de disolución automática o de pleno derecho de la sociedad, como ocurría antes de la Ley $\mathrm{N}^{\circ} 20.382$, de manera que la autorización referida no puede extrapolarse a la venta o cesión de acciones; ni siquiera cuando esta constituya el antecedente de la disolución ulterior, en caso de no recuperarse oportunamente la pluralidad.

B) Otra alternativa consiste en limitar la aplicación del art. 28 de la LSGR a aquellas causales de disolución cuya configuración depende (i) de la voluntad de la pluralidad unificada de los socios -fundadores o posteriores-, manifestada en el estatuto social (art. $103 \mathrm{~N}^{\circ} 6$ de la LSA), o (ii) de la voluntad de la sociedad como tal expresada a través de sus órganos $-\mathrm{y}$ concretamente por la junta de accionistas- (art. $103 \mathrm{~N}^{\circ} 3$ ), quedando extramuros de la norma referida las conductas o decisiones de los accionistas individualmente considerados (como sería el caso del art. $103 \mathrm{~N}^{\circ} 2$ 
de la LSA). De esta forma entonces, la sociedad se disolvería aun cuando los acreedores no hubiesen manifestado su autorización en tal sentido, pues el hecho jurídico que genera dicha consecuencia tendría aquí un origen esencialmente extrasocietario. La transferencia de acciones produce efectos en la sociedad, pero no es un acto de la sociedad.

Creemos sin embargo que esta solución va en contra del sentido y la finalidad que tuvo el legislador al incorporar la exigencia de autorización previa del art. 28 citado, en orden a cautelar los intereses de los terceros que han recibido garantías personales de la SGR y que, por un hecho esencialmente voluntario de alguno(s) de sus accionistas, termina disolviéndose. Por lo demás, la distinción planteada -entre voluntad intra y extra societaria- no incardina tampoco en el texto de la norma referida, que consagra el requisito apuntado en términos tan amplios que hasta terminan siendo ambiguos y confusos.

C) Una tercera posibilidad pasa por asignarle a la falta de autorización previa de los acreedores el carácter de conditio iuris de la cual pende la eficacia del respectivo acto o contrato que genera la unipersonalidad, la que operará en caso de no recuperarse la pluralidad de accionistas en el plazo legal. En otros términos, el acto o contrato que origina la unipersonalidad sería válido ab initio, pero sus efectos serán inoponibles a los terceros garantizados a menos, claro está, que dentro del plazo referido se restaure la pluralidad perdida.

Tampoco parece ser esta la respuesta a la interrogante planteada, pues la incertidumbre jurídica que genera la hace impracticable a nuestro entender:

a) Desde luego, la hipótesis planteada nos llevaría a definir en primer término si la inoponibilidad del acto o contrato potencialmente idóneo para provocar la disolución en este caso, por falta de concurrencia de los terceros garantizados y ulterior lesión de sus derechos adquiridos, se extiende al seńalado acto o contrato en su totalidad o si, por el contrario, solo lo afecta en aquella parte que genera concretamente la unipersonalidad. Semejante tarea, pues, nos sitúa en un escenario dogmático especialmente complejo, con consecuencias jurídicas objetiva y subjetivamente cuestionables:

i) Primero, y considerando que la inoponibilidad constituye una sanción legal cuyos alcances deben circunscribirse solo a aquellos efectos del acto jurídico válido que perjudiquen a los terceros relativos ${ }^{63}$, habría que entender entonces que el que origina en este caso la unipersonalidad sería

63 Alessandri R., Arturo, Somarriva U. Manuel y Vodanovic H., Antonio (1998) Tratado de Derecho Civil. Parte Preliminar y General, Tomo II. Santiago: Ed. Jurídica de Chile, p. 353. 
válido y oponible en todo, menos en una acción (la necesaria para evitar la disolución ex art. $103 \mathrm{~N}^{\circ} 2$ ).

ii) Asimismo, y como apuntan Delgado y Parra ${ }^{64}$, "la inoponibilidad es una ineficacia (en sentido estricto) relativa, es decir, solo respecto de ciertos sujetos, cuya situación jurídica no queda afectada por la conclusión de un contrato -válido- por otras personas", lo que en la situación aquí planteada nos llevaría a concebir como posible el que una sociedad se encuentre disuelta para unos terceros absolutos, pero vigente para los terceros acreedores ex art. 28 de la LSGR, lo que no es posible obviamente.

b) Por otra parte, el fenómeno de la unipersonalidad sobrevenida de la SGR puede derivarse no solo de actos y contratos entre vivos a título gratuito u oneroso, sino también de asignaciones mortis causa -herencia o legado- respecto de los cuales la ineficacia o inoponibilidad de la respectiva asignación a terceros no resulta aplicable como sanción.

Debe reconocerse, no obstante, que el problema aquí planteado parece presentarse con menor intensidad en los casos de transmisión de acciones de una SGR abierta, en donde la inoponibilidad a los terceros surge ex lege y de manera indirecta, como consecuencia precisamente de la prohibición de registrar a que se refiere el art. 107 de la LSA, en relación con el art. 17 de su Reglamento.

Respecto de las sociedades cerradas no existe en cambio una norma como la del art. 107, a lo que se suma la circunstancia de que en estas el registro de las acciones transmitidas no puede condicionarse por la sociedad a la autorización previa a que se refiere el art. 28 de la LSGR. Como ya se explicó, tal autorización resulta necesaria para evitar la disolución de la SGR más no para la eficacia de los actos jurídicos que generan la unipersonalidad como presupuesto de la causal.

c) Por último, hemos dicho también que la libre cesibilidad de las acciones constituye un principio configurador de la sociedad anónima como sociedad de capital, principalmente en las abiertas y cotizadas, lo que por esta vía perdería sin embargo toda vigencia y certeza.

D) Descartadas las alternativas precedentes, podría sostenerse entonces que el art. 28 de la LSGR hace inaplicable a este subtipo societario la causal de disolución del art. $103 \mathrm{~N}^{\circ} 2$ de la LSA. En otros términos, la SGR subsistiría con un solo accionista aun cuando no se obtuviese la autorización de los acreedores en el plazo legal de 10 días, ya indicado, lo que llevaría a concluir además que junto con la unipersonalidad originaria y sobrevenida de una sociedad de capital, reconocida recientemente en los arts. 424 y 444 del C. de Comercio para la SpA -respectivamente-, el 
ordenamiento jurídico chileno reconocería también esta particular figura de unipersonalidad sobrevenida de una sociedad anónima; sin perjuicio, claro está, del caso especial que contempla el art. 71 bis, inc. $2^{\circ}$, de la LSA, incorporado por la Ley $\mathrm{N}^{\circ} 20.382$.

Esta hipótesis, si bien parece armonizar con la intención del legislador en orden a proteger en estos casos el interés de los terceros que han recibido la garantía personal de la SGR, contradice no obstante el propósito manifestado por el mismo legislador en la seńalada ley $\mathrm{N}^{\circ} 20.382$ en cuanto a matizar - por un lado- la aplicación automática de la causal de disolución automática que comentamos, evitando en todo caso -por el otro- la permanencia indefinida de sociedades anónimas con un solo accionista $^{65}$. Todavía más, no existe en la LSGR una disposición como la que se contemplaba en el derogado art. 69 ter de la LSA, cuyo inciso $4^{\circ}$ aclaraba expresamente que "En caso que todos los accionistas ejercieren la opción de enajenar la totalidad de sus acciones al controlador o ejercer el derecho a retiro en su caso, a la sociedad no le será aplicable la causal de disolución establecida en el $N^{\circ} 2$ ) del artículo103, a menos que el controlador decida lo contrario y asi lo señale conforme al artículo 213 de la Ley $N^{\circ}$ 18.045".

En consecuencia, tampoco parece posible concluir ex art. 28 de la LSGR, la inaplicabilidad de la causal de disolución del art. $103 \mathrm{~N}^{\circ} 2$ de la LSA.

E) En síntesis, y sin desconocer la complejidad del problema planteado, creemos nosotros que la aplicación del art. 28 de la LSGR a los casos de disolución de una SGR ex art. $103 \mathrm{~N}^{\circ} 2$ de la LSA, debe analizarse a la luz de los mismos principios y objetivos de protección a los terceros interesados que ha tenido en cuenta el legislador al establecer la limitación contemplada en el art. 107 de la LSA, ya mencionado.

Según esto, pues, el requisito de autorización previa de los acreedores garantizados por la SGR, en cuanto formalidad habilitante para que opere en estos casos la disolución de la misma por reunirse todas las acciones en una sola mano, constituye también una modificación de la regla general contemplada a su turno en el art. 12 inc. $2^{\circ}$ de la LSA, en relación con el art. 17 de su Reglamento. En estos casos, en efecto, la sociedad deberá abstenerse de inscribir en el Registro de Accionistas la transferencia o transmisión de acciones que origina la unipersonalidad, en tanto y en

65 La ley $\mathrm{N}^{\circ} 20.382$ (D.O. de 20 de octubre de 2009) fijó en efecto el plazo de 10 días a que se refiere el texto actual del art. $103 \mathrm{~N}^{\circ} 2$ de la LSA y derogó al mismo tiempo el art. 69 ter de la misma ley, que contemplaba la única figura unipersonal sobrevenida de una sociedad anónima reconocida por la ley chilena hasta entonces. La seńalada causal de disolución sin embargo, tras la incorporación de la figura unipersonal originaria de una sociedad de capital - SpA- al derecho chileno de sociedades, carece de justificación y de utilidad. 
cuanto no se le acredite que la disolución de la sociedad -que dependerá en último término de lo que el accionista único haga o deje de hacer en el plazo de 10 días del art. $103 \mathrm{~N}^{\circ} 2$ de la LSA- ha sido autorizada previamente por los acreedores a que se refiere el seńalado art. 28 de la LSGR.

\section{c) Autorización administrativa de disolución por unipersonalidad sobrevenida (art. 107 de la LSA)}

El segundo aspecto que nos proponemos dilucidar consiste en fijar el concreto alcance de la autorización a que se refiere el art. 28 inc. $1^{\circ}$ de la LSGR, en relación con lo que dispone a su turno el art. 107 de la LSA respecto de las sociedades anónimas abiertas. Ambas disposiciones, en efecto, condicionan la disolución por unipersonalidad sobrevenida de la sociedad anónima abierta a sendas autorizaciones previas - de los terceros garantizados en el primer caso y de la SVS en el segundo-, lo que nos lleva a definir aquí la forma en que ambas conviven.

Según el art. 28 de la LSGR, recordemos, la disolución, división y fusión de la SGR requiere de la autorización previa y por escrito de los dos tercios de los terceros que han recibido certificados de fianza emitidos por la sociedad. Según el art. 107 de la LSA, por su parte, la autorización previa de la SVS no está sujeta a limitantes subjetivas o materiales de ninguna especie, de manera que para otorgarla el ente fiscalizador deberá tener en cuenta los intereses de todos los terceros que han contratado con la sociedad, sin porcentajes ni proporciones definidas, velando en cada caso por el efectivo otorgamiento de las medidas de resguardo a que se refiere la norma citada.

En consecuencia, y sin perjuicio de lo que hemos dicho supra respecto de la causal del art. $103 \mathrm{~N}^{\circ} 2$ de la LSA, la disolución de la SGR abierta por la unipersonalidad sobrevenida derivada de la transferencia $o$ transmisión de acciones será inoponible a la sociedad, a los demás accionistas y a los terceros en tanto no se cumpla con las formalidades habilitantes contempladas tanto en el art. 28 de la LSGR cuanto en el art. 107 de la LSA. Dicho en otros términos, la sola autorización de los $2 / 3$ de los acreedores garantizados por la SGR no suple la autorización adicional que debe dar la SVS en estos casos, que apunta a cautelar a todos los terceros que han contratado con la sociedad, sin distinción; mientras que la sola autorización dada por esta última tampoco reemplaza a la que se exige $e x$ art. 28, que apunta a una categoría o grupo concreto de terceros.

\subsection{7) Fiscalización de la SGR y sistema de clasificación}

Para concluir con esta investigación, debemos destacar que la actividad de las sociedades de garantía recíproca, incluso las cerradas, se 
encuentra sometida a una intensa intervención externa de la administración pública a través de la SBIF, lo que genera -o puede generar- algunos problemas derivados de la importante dimensión que asume el ejercicio de la potestad reglamentaria en este ámbito o sector de la actividad económica ${ }^{66}$. Por ello, precisamente, una parte importante de la doctrina comparada ${ }^{67}$ ha optado por asumir una posición más pragmática en este sentido, partiendo del supuesto - como apunta ReYes ${ }^{68}$ - de que "no es necesario justificar el sometimiento de una actividad hoy en día eminentemente privada a todo un elenco de disposiciones jurídico-públicas”.

La operatividad y competitividad del sistema de garantías recíprocas depende sin embargo de la solvencia y liquidez de las instituciones que lo integran, lo que constituye una constante no solo en Chile sino en la totalidad de los ordenamientos jurídicos que con diversos matices lo reconocen. Por lo mismo, y considerando además la estrecha incidencia que tienen estas entidades en los niveles de riesgo crediticio que asumen las instituciones financieras que reciben sus garantías, el régimen de fiscalización aplicable a ellas no puede quedar sujeto a la sola regulación del derecho de sociedades y, por ende, a las normas de fiscalización que este contempla según el tipo societario de que se trate.

Pues bien, más allá de la autorización previa de funcionamiento de la SGR -ya mencionada- y de los mecanismos comunes de fiscalización de una sociedad anónima, la fiscalización en Chile de la SGR se estructura principalmente con base en los siguientes aspectos distintivos:

\section{a) Fiscalización de la administración por auditores externos inde- pendientes}

Aun cuando la SGR se constituya como una sociedad anónima cerrada, el art. 20 de la LSGR establece que sus estados financieros serán

66 La LSGR destaca especialmente este particular aspecto en su art. 22, al seńalar que " $L a$ Superintendencia podrá dictar instrucciones generales para la aplicación de la presente ley".

67 Por todos Martín-Retortillo Baquer, Sebastián (1991) Derecho administrativo económico, V. II, Madrid: La Ley, p. 126 y ss. y 144 y ss. Citado también por Reyes Palá, Laguna (2002). "Fórmulas renovadas de financiación de la Pyme: algunos aspectos del régimen jurídico de las sociedades de garantía recíproca”, en Derecho de Sociedades (Libro Homenaje a Fernando Sánchez Calero), Vol. IV. Madrid: Mc Graw Hill, p. 4236, nota 15. Debe aclararse, sin embargo, que según el art. $1^{\circ}$ de la ley española 1/1994, de 11 de marzo, "las sociedades de garantía recíproca tendrán la consideración de entidades financieras", lo que en el caso español parece justificar la intervención activa de la administración pública. Distinto es sin embargo el caso de la ley chilena, que las considera como tales instituciones financieras solo para los efectos de recibir y administrar los aportes estatales de recursos a que se refiere el art. 32 de la LSGR, de manera tal de evitar en tales casos el pago del impuesto de timbres y estampillas en conformidad al art. $24 \mathrm{~N}^{\circ} 13$ del D.L. $\mathrm{N}^{\circ} 3475$, de 1980. 
siempre auditados por auditores externos independientes inscritos en el registro de auditores a cargo de la SVS. La exigencia apuntada constituye, por lo mismo, una notoria excepción a las diversas alternativas que en este sentido contempla el art. 51 de la LSA y que van, tras la modificación introducida por la Ley $\mathrm{N}^{\circ} 20.382$, desde la opción de la junta de accionistas en orden a designar anualmente inspectores de cuentas o auditores externos independientes, hasta el diseño de un sistema estatutario autónomo y distinto al supletorio que establece la LSA.

\section{b) Sistema especial de clasificación de la SGR}

Un aspecto característico del modelo chileno de SGR lo constituye el mecanismo especial de clasificación contemplado en los arts. 17 y 18 de la LSGR, independiente por cierto del sistema general de clasificación de riesgo establecido en la Ley $\mathrm{N}^{\circ} 18.045$ para todas las sociedades anónimas fiscalizadas por la SVS, incluidas las SGR.

Pues bien, la comprensión de este diseño estructural de supervisión administrativa, que la ley le encomienda en este caso a la SBIF, presupone definir previamente algunos aspectos relevantes en cuanto a legitimidad y justificación de la misma, según pasamos a revisar.

b.1) La asimilación relativa de la SGR a las instituciones financieras.

Según el art. 32 de la LSGR, se faculta a los organismos y servicios públicos allí mencionados para proporcionar a las instituciones de garantía recíproca recursos de fomento y financiamiento para la Pyme. Para estos efectos -indica en su inc. $2^{\circ}$-, estas entidades serán consideradas instituciones financieras".

La norma citada, si bien parece inspirarse nuevamente en su antecedente español entre otros, se distancia notoriamente del mismo por el carácter lejano que aquella le asigna a este declarado parentesco entre la SGR y las instituciones financieras. El art. $1^{\circ}$ de la ley espańola 1/1994, de 11 de marzo, señala en efecto que "las sociedades de garantía reciproca tendrán la consideración de entidades financieras", para todos los efectos y sin distinción (lo que parece justificar-obiter dicta- la intervención activa de la administración pública y del Banco de Espańa en ese sistema ${ }^{69}$, a diferencia de la ley chilena que las considera como tales instituciones financieras solo para los efectos de recibir y administrar los aportes estatales de recursos a que se refiere el art. 32 ya citado, evitando así el pago

69 El carácter de entidad financiera de la SGR en la legislación española no admite duda, considerando además que el origen de la norma citada en el texto se encuentra en la Ley $\mathrm{N}^{\circ}$ 26/1988, de 29 de julio, sobre Disciplina e Intervención de las Entidades de Crédito (BOE 30-7; corregido por BOE 4-8-1989). 
del impuesto de timbres y estampillas por aplicación del art. $24 \mathrm{~N}^{\circ} 13$ del D.L. $\mathrm{N}^{\circ} 3475$, de $1980^{70}$.

En otros términos, la declaración que hace la LSGR en su art. 32 inc. $2^{\circ}$ no pretende, ni con mucho, atribuirle a la SGR la naturaleza de institución financiera y menos someterla a la regulación aplicable a estas últimas, contenida principalmente en la LGB y en la Recopilación Actualizada de Normas -RAN- de la SBIF. Lejos de ello, reitero, la LSGR se limita a asimilarlas instrumentalmente con el solo propósito recién descrito, de manera que la labor reguladora y de fiscalización de la SBIF, justificada sin duda por la función intermediadora que se le asigna a la SGR en el sistema crediticio, queda acotada consecuencialmente al preciso ámbito competencial que se le fija en los arts. 17 y ss. de la seńalada ley.

El referido mecanismo de regulación y fiscalización de la SGR, con todo, no es novedoso ni constituye tampoco una creación reciente del legislador. Se trata, por el contrario, de un diseńo de larga data en el ordenamiento jurídico chileno, cuyo antecedente más claro puede encontrarse ya en la Ley No 18.690 (D.O. de 2 de febrero de 1988), sobre Almacenes Generales de Depósito (Warrant). El art. 31 de la seńalada ley (art. 17 de su Reglamento) es casi idéntico en efecto al art. 18 de la LSGR, estableciendo para dichas empresas un sistema de clasificación y fiscalización periódica que la LSGR replica en todo según pasamos a revisar. Lo propio ocurre con la autorización previa de funcionamiento a que nos referimos supra, idéntica también a la que se exige en el art. 30 de la Ley $\mathrm{N}^{\circ}$ 18.690 .

b.2) Categorización de la SGR y evaluación especial externa.

70 En el Primer Informe de la Comisión de Pymes de la Cámara de Diputados se dejó en claro que la cualificación de la SGR como sociedad financiera tenía un fin puramente instrumental, orientado a evitar como se dijo la carga impositiva de los aportes de CORFO. Según la referida Comisión, "las alternativas serían modificar el Decreto Ley antes referido [ $\mathrm{N}^{\circ} 3.475$ de 1980), incluyéndolos expresamente [los créditos dados por CORFO] $o$ calificar a las Sociedades de Garantía Reciproca como instituciones financieras. Sin embargo, ello podría implicar la existencia y aplicación de normas legales que dicen relación con aquellas, pero que no tengan que ver con las Sociedades de Garantía Reciproca. Los representantes del Ejecutivo estimaron que la primera solución podría retrasar en demasia el proyecto". En definitiva, y para zanjar el problema planteado, los diputados Sres. Delmastro, José Antonio Galilea, Masferrer, Urrutia y González formularon una indicación para incorporar al art. $1^{\circ}$ del proyecto de ley el siguiente inciso tercero:

"Para todos los efectos legales las Sociedades de Garantía Reciproca serán consideradas como instituciones financieras". Más claro quedó este punto durante la discusión del proyecto en la seńalada Cámara Baja, en donde el diputado Sr. Galilea reiteró que la asimilación de las sociedades de garantía recíproca a las instituciones financieras se había incorporado al proyecto "con el claro objetivo de liberarlas del pago del impuesto de timbres y estampillas". La norma fue trasladada finalmente al art. 32 del proyecto, mediante indicación aprobada en segundo trámite constitucional por la Comisión de Economía del Senado. 
Según el art. 18 de la LSGR, la SBIF llevará un Registro de Instituciones de Garantía Recíproca "en el cual se clasificarán en categorías $A$ o B". En la primera categoría -agrega la norma- se incluirán aquellas sociedades que, además de cumplir los requisitos formales y de solvencia ya analizados (art. 17 LSGR), "cuenten con un informe favorable de evaluación emitido por una entidad independiente de la sociedad, especializada en la materia, por lo menos en dos épocas del año". Tales entidades, a su turno, "deberán estar inscritas en el Registro abierto con tal fin por la Superintendencia, y quedarán sujetas para estos efectos a su reglamento y control"71.

De las normas citadas se desprende entonces que el sistema de clasificación de la SGR en Chile, tomado como se dijo supra de la Ley $\mathrm{N}^{\circ}$ 18.690, presenta diversas particularidades que conviene destacar:

a) En primer término, la clasificación como SGR clase A o B genera importantes consecuencias prácticas de cara al desarrollo del giro social, pues solo las primeras -clase A- podrán otorgar garantías a entidades bancarias y financieras (art. 19 inc. $1^{\circ}$ de la LSGR). Si bien la ley no lo señala derechamente, lo cierto es que la consecuencia última es precisamente esa si consideramos que la SBIF solo podrá considerar, para efectos de la calificación de las garantías recibidas por las referidas entidades, los Certificados de Fianza emitidos por las sociedades clase A. Los bancos, por lo mismo, difícilmente estarán dispuestos a recibir garantías de sociedades clase $\mathrm{B}$, dada la consiguiente obligación legal de provisionar el mayor riesgo asumido.

b) En segundo lugar, y relacionado con lo anterior, el mismo art. 19 señala que los Certificados categoría A "servirán de garantía para los efectos de la ampliación del limite individual de crédito a que se refiere el artículo $84, N^{\circ} 1$, de la Ley General de Bancos (...)", lo que constituye un importante estímulo para los bancos al momento de decidir el otorgamiento de un crédito garantizado por esta vía.

c) Sólo las entidades especializadas autorizadas por la SBIF pueden llevar a cabo la función evaluadora que la ley establece, cumpliendo para ello los requisitos que la propia SBIF establezca (art. 18 inc. $5^{\circ}$ de la LSGR, en relación con la Circular $\mathrm{N}^{\circ} 1$ SBIF, de 16 de octubre de 2007).

d) Por último, resulta imposible comprender cabalmente los alcances de este mecanismo especial de clasificación de la SGR si al mismo tiempo no se revisan, con visión sistemática por cierto, las normas reglamentarias dictadas por la SBIF en materia de avales y fianzas y que repercuten, no obstante su carácter general, en el tratamiento de la concreta materia que aquí se analiza.

\footnotetext{
71 El Reglamento a que se refiere la norma legal es la Circular $\mathrm{N}^{\circ} 1$ de la SBIF, de 16 de octubre de 2007, que establece "Normas generales para firmas evaluadoras de instituciones de garantía recíproca”.
} 
Considerando en efecto que la señalada clasificación en $A$ o $B$ no coincide con ninguno de los parámetros nacionales o internacionales de clasificación de riesgo, la SBIF ha optado por asimilar esta curiosa opción legislativa a los rangos de clasificación local e internacional ya conocidos y generalmente aceptados, de manera de estandarizar de algún modo -en pie forzado y sin una base legal definida a mi entender- los criterios de clasificación de riesgo aplicables comúnmente a todos los entes fiscalizados. Señala en este sentido el Capítulo B-1 del Compendio de Normas Contables de la SBIF, apartado 4.1.a), en relación con el apartado 2.1 del mismo capítulo:

"Cuando el avalista o fiador, incluidas las Sociedades de Garantía Reciproca, sea una entidad calificada en alguna categoría asimilable a grado de inversión por una firma clasificadora local o internacional reconocida por esta Superintendencia, la calidad crediticia del deudor o grupo de deudores directos, según corresponda, podrá ser sustituida en la proporción que corresponda a la exposición respaldada, por la calidad crediticia del deudor indirecto, asociando a cada categoría las siguientes equivalencias:

$\begin{array}{ccc}\text { Categoría } & \begin{array}{c}\text { Equivalencia para Escala } \\ \text { Internacional }\end{array} & \begin{array}{c}\text { Equivalencia para Escala } \\ \text { Nacional }\end{array} \\ \mathrm{AAA}-\mathrm{Aaa} & \mathrm{A} 1 & \mathrm{~A} 1 \\ \mathrm{AA}-\mathrm{Aa} & \mathrm{A} 1 & \mathrm{~A} 1 \\ \mathrm{~A}-\mathrm{A} & \mathrm{A} 1 & \mathrm{~A} 2 \\ \mathrm{BBB}-\mathrm{Baa} & \mathrm{A} 2 & \mathrm{~A} 3\end{array}$

También se podrá proceder a la sustitución antes indicada cuando el avalista, fiador o reafianzador sea:

i) el fisco, la CORFO o el FOGAPE, asignándoles para este efecto la categoría A1;y

ii) deudores indirectos, distintos a los señalados en el número anterior, que cuenten con estados financieros auditados y se encuentren clasificados por el banco, según las disposiciones de este Capitulo, en una categoría superior a A3 y a la del deudor directo".

De esta forma entonces, la clasificación de una SGR como institución clase "A" será equivalente a una clasificación que va del "AAA" al "Baa" o "BBB", lo que introduce un factor de discriminación en la asignación del riesgo que la LSGR no contempla ni parece tolerar sin embargo. La advertencia no es trivial por lo demás, pues lo dicho constituye un factor que incide directamente en la consolidación de este sistema 
de garantías y en su eficacia como alternativa para la banca a la hora de otorgar un crédito. En este esquema, pues, la opción entre respaldar un crédito con un Certificado de Fianza o con una garantía real dependerá, obviamente, de la calificación que se le asigne en cada caso a la sociedad emisora de dicho Certificado, pudiendo ocurrir sin embargo que esta, pese a integrar el club de las empresas "A" según la LSGR, sea considerada por la entidad evaluadora $-y$ por ende por el banco respectivo- como una entidad "BBB", perdiendo toda competitividad y resignando por lo mismo uno de los fines primordiales de la ley, en orden a dar movilidad a las garantías reales cautivas en el sistema financiero.

\section{3.) NATURALEZA JURÍDiCA DE LA FIANZA OTORGADA POR LA SGR: ¿ACTO CIVIL O ACTO DE COMERCIO?}

Según el art. $1^{\circ}$ de la Ley $\mathrm{N}^{\circ} 18.046$, la sociedad anónima es siempre comercial aun cuando se forme para un objeto civil, lo que plantea el problema de determinar si tal categorización se extiende o no, ope legis, a los actos y contratos de naturaleza civil que aquella ejecute o celebre.

Mucho se ha discutido sobre este aspecto en particular, tanto en Chile como en el derecho comparado, sin que exista una única solución o tendencia:

a. Por un lado, en efecto, están quienes entienden que la naturaleza mercantil que la ley le asigna a la sociedad anónima comercializa todos los actos que esta realice, cualquiera sea su naturaleza originaria. Es lo que se sostiene por un sector de la doctrina en Francia, según la cual las sociedades comerciales son creadas precisamente para hacer comercio, de manera que sus actos serán siempre actos de comercio ${ }^{72}$.

En España, el art. 3 de la derogada Ley de Sociedades Anónimas de 1989 establecía que la sociedad anónima, "cualquiera que sea su objeto, tendrá carácter mercantil"73, lo que llevó a una parte de la doctrina a sos-

\footnotetext{
72 Por todos Ripert, Georges (1983). Traité Elementaire de Droit Comercial, Tomo I, $11^{\text {a }}$ edición. París: Librairie Générale de Droit et Jurisprudence, pág. 212. Sobre esta tesis puede consultarse la jurisprudencia citada por GUYENOT, según la cual se presume que los actos realizados por los comerciantes son mercantiles. (Guyenot, Jean (1975) Derecho Comercial, Vol. 1. Buenos Aires: Ediciones Jurídicas Europa-América, pp. 136 y ss. Como apunta UBILlA, sin embargo, una presunción semejante no tiene lugar en el derecho chileno, lo que se ve reforzado por la historia fidedigna del establecimiento del Código de Comercio. En el proyecto de Ocampo, en efecto, se incluía precisamente una presunción semejante (art. 9 del proyecto), la que fue eliminada por la Comisión Revisora. Ubilla (pp. 14 y 15).

73 En similares términos se pronuncia el actual art $2^{\circ}$ de la Ley de Sociedades de Capital (Real Decreto Legislativo $1 / 2010$, de 2 de julio), que seńala: "Carácter mercantil.-Las sociedades de capital, cualquiera que sea su objeto, tendrán carácter mercantil".
} 
tener que el objeto de la misma era del todo irrelevante de cara a la mercantilidad de la sociedad, pudiendo incluso tener uno sin fines de lucro. Al tenor de esta norma - dice Broseta ${ }^{74}$ - "ha de considerarse igualmente posible la constitución de una sociedad anónima que no pierde su naturaleza mercantil, aun cuando no persiga una finalidad lucrativa”.

En Chile, la tesis que se analiza es sostenida entre otros por BAEzA ${ }^{75}$, quien a partir de la mercantilidad formal ya dicha y aplicando el principio de accesoriedad, concluye que los actos de naturaleza civil de la sociedad anónima quedan comercializados en virtud de dicho principio.

b. En el lado opuesto, quienes estiman en Chile que la mercantilidad formal de la sociedad anónima no involucra necesariamente la de todos sus actos se fundan, también y curiosamente, en el mismo principio de accesoriedad de los actos de comercio, aunque en su vertiente inversa ${ }^{76}$. Como señala Puelma" ${ }^{77}$, en efecto, "Los comerciantes, no obstante su calidad de tales pueden realizar actos no comerciales. La misma situación ocurre tratándose de sociedades que son mercantiles por su giro, aplicando lo dispuesto en el art. 2059 del Código Civil, que también puede realizar actos civiles, pues sigue vigente el art. $3^{\circ}$ del Código de Comercio que determina cuáles son los actos de comercio (...). La circunstancia que la ley le otorgue el carácter mercantil a la sociedad anónima, no significa que cualesquier acto de ella tenga tal carácter (...)”.

Compartimos esta opinión en lo sustancial por cuanto, de estimarse que la mercantilidad de la sociedad anónima lo es también de todos sus actos y contratos, aun los de naturaleza civil, implica crear sin más actos de comercio que la ley no contempla en el art. 3 del C. de C., cuya enumeración es taxativa a nuestro entender ${ }^{78}$. Sin embargo, no parece asertado sostener que la mercantilidad formal de la sociedad anónima mercantiliza por accesoriedad los actos y contratos de naturaleza civil que conforman su objeto social, pues, como apunta PUGA ${ }^{79}$, "la accesión no dice relación con una forma jurídica, sino con una actividad económica [...].

74 Broseta Pont, Manuel (2002) Manual de Derecho Mercantil, $1^{\text {a }}$ edición a cargo de Fernando Martínez Sanz, Vol. 1. Madrid: Tecnos, p. 322.

75 Baeza Ovalle, Gonzalo (2003) Derecho Comercial, Tomo II. Santiago: LexisNexis, p. 1050 .

76 De conformidad a los arts. $1^{\circ}$ y $3 \mathrm{~N}^{\circ} 1$, inc. $2^{\circ}$, del C. de C., el principio de accesoriedad no implica únicamente la mercantilización de actos realizados por no comerciantes (art. $1^{\circ}$ ), sino también la desmercantilización de actos realizados por comerciantes (art. $3 \mathrm{~N}^{\circ} 1$, inc. $2^{\circ}$ ).

77 Puelma, 2011, Tomo II, 467. Este autor distingue sin embargo entre los actos externos y los actos "internos" de la sociedad ("constitución y modificación, aportes, sesiones de directorio, juntas, etc.”), limitando a estos últimos la mercantilidad formal que les imprime el art. $1^{\circ}$, inc. $2^{\circ}$, de la LSA.

Puga (2011) 92. 
Así, resulta que la sociedad anónima formada para negocios civiles (v. gr. una sociedad de profesionales; una sociedad de servicios de salud; una sociedad inmobiliaria; una sociedad agrícola...) sería comercial por su forma, pero su actividad sería civil y, por lo mismo, imposible de hacer de ella un comerciante".

En otros términos, nos parece que no es posible aplicar la ley comercial por analogía y, por ende, no es factible tampoco que existan actos de comercio fuera del art. 3. El acto será mercantil solo si está contemplado en el señalado artículo $3^{\circ}$ o, por excepción, si alguna ley especial le otorga tal calidad (v. gr. art. $1^{\circ}$ de la Ley No18.046), pero no pueden configurarse actos de comercio por analogía. Por ende, al seńalar la ley que la sociedad anónima es siempre mercantil, aun cuando su objeto sea civil, no ha querido alterar ni mucho menos derogar a nuestro entender los fundamentos de la tesis objetiva del acto de comercio, que recoge precisamente el C. de C., sino simplemente someter a este tipo societario a las normas aplicables a los comerciantes en general, incluidas las de carácter tributario y las que regulan su régimen de quiebra.

En síntesis, de lo dicho hasta aquí se desprende que los actos y contratos celebrados por la Sociedad Anónima de Garantía Recíproca, en ejecución de su giro exclusivo de naturaleza civil (el contrato de fianza no constituye acto de comercio en Chile), no pueden ser considerados como mercantiles por accesoriedad. Distinto puede ser sin embargo el caso del beneficiario de dicha garantía, la que sí que puede adquirir un carácter comercial cuando la obligación principal garantizada por aquella tiene tal naturaleza (art. $1^{\circ}$ del C. de Comercio).

\section{3) SGR Y FINANCIAMIENTO DEL ESTADO: PROGRAMAS DE LÍNEAS DE CRÉDITO CORFO A FONDOS DE GARANTÍA}

Como se dijo supra, el Título VIII de la LSGR, arts. 32 y siguientes, faculta expresamente a los organismos y servicios públicos que mencio$\mathrm{na}^{80}$ para que proporcionen a las SGRs, en conformidad a las normas

80 Un aspecto que se discutió durante el trámite legislativo consistió en determinar si, dada la amplitud de la norma, dentro de estos “organismos y servicios públicos” debía incluirse o no al Banco del Estado. Al respecto, el Segundo Informe de la Comisión de Economía del Senado deja en claro que la seńalada entidad bancaria no puede considerarse dentro aquellas a las que se refiere la norma, lo que se desprende del artículo $2^{\circ}$ del D.L. $N^{\circ}$ 2079, que fija el texto de la ley orgánica del Banco del Estado de Chile. Según esa disposición, en efecto, dicho banco se regirá preferentemente por las normas de su ley orgánica y, en lo no previsto en ella, "por la legislación aplicable a las empresas bancarias y demás disposiciones que rijan para el sector privado. No le serán aplicables, por tanto, las normas generales o especiales relativas al sector público, salvo que ellas dispongan de modo expreso que han de afectar al Banco del Estado de Chile”. En consecuencia, el artículo 
legales que los rigen respectivamente, recursos destinados a potenciar el funcionamiento actual de este nuevo mecanismo de financiamiento a la Pyme.

Por esta vía entonces, y tal como ocurre en todos los sistemas comparados de garantía recíproca - con sus diversos matices, claro está-, a través del respaldo estatal la ley chilena pretende consolidar las bases de un sistema que ha sido diseńado con una clara vocación de autonomía en el largo plazo y que aspira, por lo mismo, a lograr un grado de madurez sistémica que se refleje finalmente en un desempeño autosustentado de esta industria, independizada en gran medida del apoyo financiero del Estado. En su primera etapa sin embargo, tal funcionamiento depende necesariamente de la existencia y disponibilidad de un volumen significativo de recursos financieros que el mercado, sin embargo, no está dispuesto a invertir en su totalidad; no al menos no en esta fase inicial. El panorama así descrito genera por ende, tal como lo entendió el legislador al incorporar las alternativas de financiamiento contempladas en el Título VIII de la LSGR, la necesidad de que el Estado le proporcione a estas entidades los recursos y la liquidez suficiente para asumir eventualmente, de manera rápida y oportuna, las obligaciones de pago de corto plazo derivadas de la ejecución de los Certificados de Garantía por parte de los acreedores garantizados, sin perjuicio de la ulterior liquidación de las contragarantías que pueda haber constituido el beneficiario.

Para la implementación de este soporte inicial, en fin, la ley contempla tres vías distintas por las que pueden optar estos organismos y servicios públicos autorizados (básicamente INDAP, CORFO y FOGAPE), las que se describen en los artículos 32, 33 y 34 de la ley respectivamente. En lo que aquí concierne, nos interesa destacar principalmente los aspectos del sistema de aporte indirecto del Estado a través de CORFO, canalizados mediante la capitalización de fondos privados de inversión administrados por la SGR (art. 33).

\section{1.) ALgUNOS ANTECEDENTES SOBRE LOS PROGRAMAS DE LÍNEAS DE CRÉDITO CORFO PARA FONDOS DE GARANTÍA}

A partir de la autorización legal expresa del art. 33 de la LSGR, que coincide por lo demás con la que se le otorga de manera genérica en

32 de la LSGR no se aplica al Banco del Estado ya que este, como se acaba de explicar, no se rige por la ley $\mathrm{N}^{\circ} 18.575$, Orgánica de Bases Generales de la Administración del Estado, cuyo texto refundido, coordinado y sistematizado se fijó por el D.F.L. $N^{\circ} 1 / 19.653$, de manera que no puede ser considerado ( $C f r$. Segundo Informe de la Comisión de Economía, en Historia..., op. cit., p. 353). 
el art. 25, letra j), de la Ley $\mathrm{N}^{\circ} 6.640$ (D.O. de 10 de enero de 1941), CORFO ha implementado y ejecutado a la fecha tres programas de línea de crédito para Fondos de Garantía administrados por instituciones de garantía recíproca, el segundo de ellos destinado a la reconstrucción post terremoto del 27 de febrero de 2010 y al que no nos referiremos en esta oportunidad.

En la actualidad, entonces, CORFO mantiene vigentes -en lo que aquí interesa- dos Programas de línea de crédito distintos, que establecen regulaciones distintas y que se aplican además en forma selectiva a entidades que, sin embargo, presentan una misma condición objetiva ${ }^{81}$. Nos referimos en concreto a los Programas IGR-I e IGR-III, este último aprobado por Resol. Ex. de 31 de agosto de 2011, del Comité Ejecutivo de Créditos, que consiste a su vez en la versión revisada del mismo Programa $I G R-I I I$, de 25 de mayo de 2011 (Resol. E. N ${ }^{\circ} 0920$, que ejecuta acuerdo $\mathrm{N}^{\circ} 27497$ del mismo Comité).

No es nuestro propósito -ni esta la oportunidad- para revisar en detalle el contenido de los referidos Programas, pues ello escapa al objeto de este estudio. Sin embargo, nos parece importante al mismo tiempo destacar en lo que sigue algunos aspectos concretos de la regulación de CORFO, por el impacto sistémico que genera de cara al buen funcionamiento de esta nueva herramienta Pyme.

\section{2.) LIMITACIÓN DEL MONTO A REAFIANZAR POR EL FONDO DE GA- RANTÍA}

En primer término, el "Programa de Linea de Crédito a Fondos de Garantía - IGR-III", apartado $2^{\circ}$, letra g), CORFO limita el monto de los certificados de fianza otorgados por las SGR a sus beneficiarios, emitidos con el respaldo del respectivo fondo de garantía, los que por regla general no pueden garantizar por ende más del $80 \%$ de los saldos insolutos de los créditos respectivos. Con ello, el $20 \%$ del riesgo involucrado en la operación de crédito debe asumirlo el acreedor, lo que constituye un vistoso desincentivo para los agentes crediticios y un obstáculo injustificado para la competitividad de la SGR frente a los instrumentos de crédito directo que entrega CORFO, de menor costo relativo por cierto, y una contradicción con la voluntad manifestada por el legislador en orden a dar movilidad a las garantías reales cautivas en el sistema financiero mediante su reemplazo por Certificados de Fianza.

81 El Programa $I G R-I$ se aplica en efecto a aquellas instituciones de garantía recíproca constituidas y que recibieron líneas de crédito antes de entrar en vigencia el programa $I G R-I I I$, el que rige a su turno para aquellas entidades que accedieron a dichos fondos con posterioridad a su entrada en vigencia. 


\section{3.) CONTRAgarantías}

A diferencia de lo que ocurre con el Programa IGR-I de CORFO, vigente para aquellas instituciones de garantía recíptoca que obtuvieron líneas de crédito antes de la entrada en vigencia del primer Programa IGR$I I I$, de 25 de mayo de 2011, el actual Programa exige en su apartado $4^{\circ}$, letra d), que los Certificados que son reafianzados por los fondos de inversión cuenten con el respaldo de garantías reales otorgadas a la respectiva SGR. Según la regla mencionada, en efecto “(...) una vez transcurridos 365 dias corridos desde la emisión del primer certificado de fianza, los montos afianzados deberán contar con respaldo de contragarantías, valorizadas según lo dispuesto en la Circular $N^{\circ} 1$ para Sociedades de garantía Reciproca de la SBIF, de al menos el 60\% del valor de los certificados vigentes". Tratándose de las IGR que soliciten por primera vez una línea de crédito a beneficio de un fondo -agrega la disposición-, el porcentaje indicado será del $20 \%$ respecto de esa primera línea, el que a partir de los 730 días corridos desde la emisión del primer certificado de fianza se incrementará al $60 \%$.

Tal exigencia, sin embargo, constituye a nuestro parecer un importante obstáculo para muchas Pyme que no cuentan con tales garantías y, por ende, una contradictio in substantia de cara a los objetivos de política pública que tuvo en mente el legislador, considerando que fue precisamente este el factor que llevó a crear un sistema indirecto de financiamiento para dichas empresas, que no dependiese de las seńaladas garantías reales.

\section{4.) COSTO DE LOS FONDOS ESTATALES}

Otro aspecto relevante, que no se contemplaba tampoco en el Programa IGR- I de CORFO -o al menos no en los términos que hoy se recogen en el Programa IGR-III- se relaciona con el costo que debe asumir la SGR para acceder a los recursos estatales de apoyo.

Según el Programa inicial $-I G R-I-$, aplicable aun para algunas sociedades de garantía recíproca como ya se explicó, las líneas de crédito estatales tienen un costo anual contingente equivalente a un 5\% de la rentabilidad del fondo de garantía constituido con el crédito subordinado de CORFO, lo que en la práctica implica una carga financiera prácticamente nula para la SGR si consideramos que la rentabilidad del fondo depende de la clase de instrumentos en que pueden invertir esos recursos. Más aun, la base de cálculo del señalado porcentaje no puede pasar del $25 \%$ de la rentabilidad del fondo, durante toda la vigencia del crédito.

En el Programa IGR-III en cambio, la tasa antes indicada es reemplazada por una tasa anual y variable de interés equivalente a TAB 360 
sobre UF, con un periodo de gracia de 24 meses durante los cuales se devengará igualmente el interés señalado para los efectos de su capitalización, al final del periodo referido (IGR-III, apartado 7, sobre "Condiciones de los créditos"). De esta forma entonces, y dependiendo del monto de la línea autorizada por CORFO en cada caso, bien puede ocurrir que el interés exigido por esta última sea incluso superior a la rentabilidad generada en el mismo periodo por la inversión de los recursos del fondo, lo que eventualmente podrá repercutir en la comisión que la SGR le cobra al beneficiario Pyme.

\section{5.) ClasificaCión DEL FONDO}

Por otra parte, la nueva condición impuesta por CORFO para liberar recursos con cargo a la línea ya aprobada, consistente en la obligación de clasificar el riesgo de los fondos de inversión que administran la SGR, constituye también un elemento distorsionador del sistema, que excede incluso el marco que establece en esta parte la LSGR ${ }^{82}$.

Según el art. 18 de la LSGR, pues, son las Instituciones de Garantía Recíproca las que deben ser sometidas al régimen especial de fiscalización diseñado por la ley, ya analizado, y no los fondos a que se refiere el art. 33 de la misma. Tal exigencia por lo mismo, que se origina en todo caso en la Circular $\mathrm{N}^{\circ} 1$ SBIF ya mencionada, sobre Evaluadoras de Sociedades de Garantía Reciproca ${ }^{83}$, constituye a nuestro entender una clara extralimitación en el ejercicio de la potestad reglamentaria de ejecución, que vulnera

82 A mayor riesgo asignado al afianzador o al fondo reafianzador, en efecto, mayores provisiones tendrán que hacer dichos bancos para otorgar sus créditos. Según ASEXMA, "De acuerdo a los requisitos que imponen las empresas clasificadoras, los fondos de SGR, en el mejor de los casos y dadas determinadas condiciones podrían alcanzar la categoría BBB-. Al tener el fondo una clasificación máxima de BBB-, sería equivalente a categoría A3 en escala nacional, esto hace que para el banco sea más conveniente operar con garantía hipotecaria que, si supera el $100 \%$ de cobertura del crédito, provisionan como A1, que con certificado de Fianza (A3)" (ASEXMA, "Análisis del impacto en las PyME...", cit., p. 4).

Si bien no compartimos el primer aserto, en cuanto a la clasificación máxima de riesgo a la que podría aspirar actualmente una SGR, lo cierto es que el régimen de fiscalización dual que aquí se plantea, amén de generar costes operativos que la ley no contempla, puede generar también una menor competitividad de estas entidades de cara a la obligación que tienen los bancos de provisionar según el riesgo crediticio involucrado, desincentivando por lo mismo el uso de este mecanismo alternativo de garantías.

83 El Capítulo II de esta Circular, apartado $1^{\circ}$ ("Contenido del Informe”), seńala expresamente que la evaluación que deben efectuar las entidades evaluadoras especiales "deberá comprender tanto a la institución misma como a cada uno de los fondos a que se refiere el artículo 33 de la Ley, que la institución administre como patrimonios independientes de ella". 
por lo mismo el principio de legalidad que informa el actuar de los órganos de la administración.

\section{6.) LIMITACIÓN DE BENEFICIARIOS Y ACREEDORES “ELEGIBLES”}

Por último, el Programa $I G R$ - III limita de manera significativa el elenco de empresas cuyas obligaciones pueden ser reafianzados por el FIP, imponiendo con ello trabas adicionales que a nuestro entender exceden con mucho el marco legal que fija la LSGR.

En su apartado $5^{\circ}$, letra c), el Programa IGR-III define a las empresas que considera "elegibles" como empresas beneficiarias de las garantías, señalando que estas "(...) podrán ser de cualquier sector económico con excepción de: "c) Adicionalmente, no serán empresas elegibles para garantizar, ni acreedores que puedan ser receptores de los certificados de fianza, aquellas empresas o instituciones en que los aportantes del Fondo, la IGR, los directores de ambos, y sus ejecutivos o las personas naturales o juridicas relacionadas a todos ellos, tengan, al momento de la emisión del certificado de garantía, relaciones de propiedad, de gestión o de acreencia directa o indirecta, en los términos establecidos en el artículo 100 de la Ley 18.045".

En otros términos, por esta vía la norma reglamentaria citada restringe severamente el margen de gestión que la LSGR le asigna a la SGR como tal y como administradora del fondo, lo que necesariamente se extrapola al funcionamiento de todo el sistema de garantías intermediadas que la ley ha procurado construir.

La LSGR no contempla en efecto prohibiciones ni restricciones específicas respecto de los beneficiarios "elegibles" y los acreedores garantizables por la SGR, reconociéndole por contrapartida a la SGR un amplio margen autorregulatorio en tal sentido (vid. arts. 2.a), 3, 5, 11 inc. $1^{\circ}$ y 33 inc. $1^{\circ}$ ). Todavía más, y como se dijo supra, la propia estructura legal de este subtipo societario contempla, como característica configuradora esencial del mismo, la posibilidad de que los beneficiarios sean precisamente los accionistas de la sociedad -vocación mutualista según se explicó-, sin que se restrinja por ello el destino de los fondos a que se refiere el art. 33 de la ley.

No obstante lo anterior, en fin, la norma reglamentaria que aquí se comenta prohíbe derechamente que la SGR, actuando como administradora del fondo de inversión, reafiance los certificados de fianza que aquella emita respecto de operaciones en las que concurra alguna de las figuras de relacionamiento ya mencionadas, muchas veces inevitables e imprevisibles incluso ${ }^{84}$. La prohibición apuntada, en efecto, que se comunica 
como se dijo a los dos intervinientes directos de la operación crediticia de que se trate -deudor beneficiario y acreedor garantizado-, se plantea en términos tan amplios que, mirada en sus extremos posibles, deja fuera del mecanismo de reafianzamiento a un enorme número de beneficiarios y acreedores legítimos, sin razones plausibles que justifiquen la notoria desproporción entre medio-fin y, por ende, la discriminación que genera el mandato administrativo.

\section{CONCLUSIONES}

La sociedad anónima de garantía recíproca ha sido incorporada al derecho chileno de sociedades con el claro y preciso objetivo de servir como vehículo idóneo de acceso de la Pyme al financiamiento oportuno y adecuado de sus proyectos y emprendimientos productivos, removiendo por su intermedio las deficiencias estructurales y de calidad de información que ha caracterizado a este importante sector de empresa.

Su categorización como sociedad anónima, sin embargo, constituye un arbitrio legislativo en cierto modo forzado, originado en la tendencia ya reiterada de encasillar las nuevas instituciones jurídicas en esquemas o estructuras ya conocidas aun cuando el parentesco entre ellas, atribuido ex lege, resulte dudoso o al menos lejano. Dicha práctica, sin embargo, genera necesariamente algunos roces e inconsistencias tipológicas y dogmáticas que bien pueden evitarse en este caso concreto, reconociendo simplemente el carácter especial o sui generis de la sociedad de garantía recíproca - no asimilable por ende a una sociedad anónima propiamente tal- y regulándola, a partir de ahí, como un ente particular que exhibe incluso una vocación mutualista que resulta impensable en una sociedad anónima.

Para el funcionamiento de este mecanismo intermediado de garantías, al menos en su etapa primaria, resulta determinante además que el Estado, a través de sus órganos administrativos autorizados, proporcione su apoyo o respaldo financiero tal como ha ocurrido en todos los sistemas comparados que contemplan este mecanismo de garantías recíprocas; incluso los puramente mutualistas. Para ello sin embargo, consideramos que las regulaciones reglamentarias de CORFO -principalmente las plasmadas en su último Programa de líneas de crédito a la IGR-son susceptibles de notorias mejoras en aquellos aspectos que hemos tratado en esta inves-

legal fijado por la LSGR y la Ley $\mathrm{N}^{\circ}$ 6.640-, bastaría con que alguna de las personas señaladas -aportantes, administradores, ejecutivos o parientes- tenga una relación " $d e$ acreencia" con un banco para que este, automáticamente, deba ser catalogado como "no elegible" en cuanto receptor del Certificado respectivo, lo que eventualmente podría dejar fuera del sistema a toda la banca. 
tigación. En su actual diseño, en fin, nos parece que dicha regulación no recoge cabalmente la voluntad manifestada por el legislador en el texto de la ley y en la historia fidedigna de su establecimiento, en orden a consolidar este mecanismo de apoyo a la Pyme con el respaldo real y eficiente del Estado (art. 32 y ss LSGR).

Del mismo modo, por último, parece indispensable que la seńalada normativa reglamentaria vigente se aplique de forma igualitaria a todas las sociedades de garantía recíproca que, en cuanto tales, presentan una misma cualificación objetiva de cara al estatuto jurídico que las rige. Debe evitarse, en fin, toda y cualesquier distinción entre ellas que no provenga de un juicio previo de razonabilidad y proporcionalidad, disipándose así cualquier atentado al derecho fundamental de igualdad y no discriminación arbitraria en materia económica.

\section{BIBLIOGRAFÍA}

- Alessandri R., Arturo, Somarriva U. Manuel y Vodanovic H., Antonio (1998) Tratado de Derecho Civil. Parte Preliminar y General, Tomo II. Santiago: Ed. Jurídica de Chile.

- Arriagada M., Gustavo (2006), "Algunas reflexiones en torno a la problemática del acceso de las Pymes a los Servicios Financieros", Santiago: SBIF, p. 13. Disponible en http://www.sbif.cl/sbifweb/ internet/archivos/DISCURSOS_4971.pdf. Consultada el 12 de octubre de 2011).

- Baeza Ovalle, Gonzalo (2003) Derecho Comercial, Tomo II. Santiago: LexisNexis.

- Banco Mundial, Enterprise Surveys, www.enterprisesurveys.org

- Broseta Pont, Manuel (2002) Manual de Derecho Mercantil, 11a edición a cargo de Fernando Martínez Sanz, Vol. 1. Madrid: Tecnos.

- Brunetri, Antonio (1960) Tratado del Derecho de las Sociedades, Tomo II, Sociedad por Acciones, Traducción de Felipe Solá Cañizares, Buenos Aires: Uteha.

- Bueso Guillén, Pedro José (2000). "El fondo de provisiones técnicas de la sociedad de garantía recíproca”, en Revista de Derecho de sociedades, $\mathrm{N}^{\circ} 15$, pp. 159-171.

- Cámara De Diputados (2006). "Radiografía de las Pymes 2006", de 29 de agosto de 2006, disponible en http://www.bcn.cl/carpeta_ temas/temas_portada.2006-08-08.7810152165).

- Congreso Nacional. Boletín No 3627-03, disponible en http:// www.bcn.cl/histley/lfs/hdl-20179/HL20179.pdf

- De La Cuesta Rute, José María y González Vásquez, José Carlos (2000) "Modificación de estatutos, aumento y reducción de capital 
social en la sociedad de garantía recíproca”, en Revista de Derecho Bancario y Bursátil, año $19, \mathrm{~N}^{\circ} 80$.

- Delgado Echeverría, Jesús y Parra Lucán, M. Ángeles (2005) Las nulidades de los contratos: en la teoría y en la práctica. Madrid: Dykinson.

- Economía Y Negocios, de 03 de abril de 2008. Disponible en http://www.economiaynegocios.cl/noticias/noticias. asp? id $=44776$ (consultada el 26 de septiembre de 2011).

- Fernández Del Pozo, Luis (2006) "La arbitrabilidad de un derecho estatutario de separación por 'justa causa' en una Sociedad Anónima. En torno a la STC 9/2005, de 17 de enero de 2005”, en Revista de Derecho de Sociedades, N²6, pp. 282 y ss.

- García Villaverde, Rafael (1980) "Las sociedades de garantía recíproca”, en Revista de Derecho Mercantil, N 155 (enero- marzo 1980), pp. 71-95.

- Goldberg, Mike / Palladini, Eric (2008). "Chile: A Strategy to Promote Innovative Small and Medium Enterprises", en Policy Research Working Paper, $\mathrm{N}^{\circ}$ 4.518, Banco Mundial.

- Guyenot, Jean (1975) Derecho Comercial, Vol. 1. Buenos Aires: Ediciones Jurídicas Europa-América.

- Hierro Anibarro, Santiago (1998) El origen de la sociedad anónima en España. Madrid: Tecnos.

- Jequier Lehuedé, Eduardo (2011). “Unipersonalidad y sociedad con un solo socio; alcances de su reconocimiento en la estructura dogmática del derecho chileno", en Revista Ius et Praxis, N¹7-2, junio de 2011, pp. 189 a 230.

- Martínez Mulero, Víctor (2005) El control de los administradores y la impugnación de sus acuerdos. Madrid: La Ley.

- Martín-Retortillo Baquer, Sebastián (1991) Derecho administrativo económico, V. II, Madrid: La Ley.

- Mensaje Presidencial A la H. Cámara De Diputados, de 10 de agosto de 2004, Boletín No 3627-03, disponible en http://www.bcn.

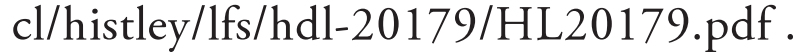

- Ministerio De Economía, Directiva de Contratación Pública $\mathrm{N}^{\circ} 7$, de la Dirección de ChileCompra. Disponible en: http://www. chilecompra.cl/index.php?option=com_phocadownload\&view=categ ory\&id=12\&Itemid=282 (consultado el 12 de octubre de 2011).

- Ministerio De Economía (2010) Primera Encuesta Longitudinal de Empresas (ELE): Resultados Seleccionados por Género. Disponible en http://www.observatorioempresas.gob.cl/LinkClick.aspx?fileticket= R5aQXxxh7d0\%3D\&tabid=90 (consultada el 26 de septiembre de 2011). 
- Puga Vial, Juan Esteban (2011). La sociedad anónima y otras sociedades por acciones por acciones en el derecho chileno y comparado. Santiago: Editorial Jurídica de Chile.

- Recomendación De La Comisión 96/280/CE, de 03 de abril de 1996. Disponible en http://eur-lex.europa.eu/LexUriServ/ LexUriServ.do?uri=OJ:L:2003:124:0036:0041:es:PDF (consultada el 23 de enero de 2012).

- Reyes Palá, Laguna (2002) "Fórmulas renovadas de financiación de la Pyme: algunos aspectos del régimen jurídico de las sociedades de garantía recíproca", en Derecho de Sociedades (Libro Homenaje a Fernando Sánchez Calero), Vol. IV. Madrid: Mc Graw Hill.

- Ripert, Georges (1950) Aspectos jurídicos del capitalismo moderno, traducción por José Quero Molares. Buenos Aires: Ediciones Jurídicas Europa-América.

(1954) Tratado Elemental de Derecho Comercial,

Vol. II, Paris: Lib. Generale de Droit de Jurisprudence.

(1983). Traité Elementaire de Droit Comercial,

Tomo I, $11^{\mathrm{a}}$ edición. París: Librairie Générale de Droit et Jurisprudence.

- Silva Walbaum, Adolfo (2008). "Normas orgánicas y funcionales de la sociedad de garantía recíproca chilena". Trabajo presentado en el marco del XIII Foro iberoamericano de sistemas de garantía y financiamiento para las micro, pequeñas y medianas empresas, Valparaíso, Chile p. 51. Disponible en http://www.redegarantias. com/archivos/web/ficheros/2010/xiii_foro_iberoamericano_de_ garantias.pdf. (consultado el 18 de enero de 2012).

- Superintendencia De Bancos E Instituciones Financieras (2007). Circular $\mathrm{N}^{\circ} 1$, de 16 de octubre, sobre Sociedades de Garantía Recíproca.

- URÍA, Rodrigo (2001) Derecho Mercantil, 28a edición. Madrid: Marcial Pons.

- Uría, Rodrigo / Menéndez, Aurelio (1999) Curso de Derecho Mercantil, Tomo I. Madrid: Civitas

- Vivante, César (1922-1926) Trattato di diritto commerciale, Tomo II, Le società commerciali, 5a edición. Milán: Francesco Vallardi.

- Yáñez, Álvaro A. (2007) "Supervisión de las Sociedades de Garantía Recíproca (SGR) en Chile", en Serie Técnica de Estudios N09, Santiago: Superintendencia de Bancos e Instituciones Financieras. 